\title{
Singing a New Song: Stephen Foster and the New American Minstrelsy
}

\section{MATTHEW SHAFTEL}

Stephen Foster's music became the backbone of the American minstrel show in the 1840s, a period of critical change for blackface minstrelsy as it grew from its countercultural class-conscious roots into an industry of racially charged entertainment. ${ }^{1}$ Foster's first minstrel songs, in contrast with his early ballads, were characterized by a simplicity of form, harmony, and melody, as well as by lyrics that ridiculed slaves and slave life, propagating the racial stereotypes that were embraced and financially supported by the successful minstrel groups of the time. Towards the end of the decade, however, many of his minstrel songs contain glimmers of a changing perception of slave life. As the antebellum era came to an end, social and political tensions moved Foster to reflection. In specific, the growing abolitionist movement and the publication of Harriet Beecher Stowe's Uncle Tom's Cabin inspired a shift in Foster's compositional style. These later songs reflect a growing uneasiness with the earlier style, ultimately leading him to a period of withdrawal from the lucrative minstrel genre. When his parlor ballads could no longer sustain him financially, however, he merged the two styles into a new hybrid genre, "the plantation melody." The songs published under this rubric use musical strategies found in the ballads and focus on nostalgic themes, thus attempting to humanize the image of the oppressed slave. This literature has been virtually ignored, but its importance in disseminating a revised view of the African American slave merits new examination. ${ }^{2}$ Focusing on structure, linear design, and text/music relationships, this essay explores the change in Foster's minstrel style as a reflection of his evolving perception of slave life. In addition, it provides historical evidence for the events that may have precipitated this stylistic shift.

White men with grease-blackened faces had entertained white audiences since well before the American Revolution, but it was not until after the war of 1812 that blackface minstrelsy became a mainstay of the American stage. ${ }^{3}$ By the midpoint of the century, this form of entertainment had

1 This essay is adapted from a talk presented at the joint meeting of the Society for Music Theory and American Musicological Society in November, 2002.

2 One extremely noteworthy exception can be found in the work of Deane L. Root, the curator of the Foster Hall Collection at the University of Pittsburgh. See especially his article: “The 'Myth-Story' of Stephen C. Foster, or Why His True Story Remains Untold” American Music Research Center Fournal, (vol. 15, 2005): 1-18.

3 Robert C Toll, Blacking Up: The Minstrel Show in Nineteenth-Century America (New York: Oxford University Press, 1974), 26. Dale Cockrell describes a long-standing English "blackface" tradition, Morris Dancing, which may be linked to Moorish-English conflicts in the 15th Century. He argues that, as with certain aspects of American Minstrelsy, the tradition of blackface goes beyond racial conflict to a connotation of overall "otherness" through the auspices of the disguise. Unlike in American Minstrelsy, however, there is no focus on race through other means, such as dialect, bodily characterizations, and publicity, such as that advertising "Ethiopian Delineators." Demons of Disorder: Early Blackface Minstrels and their World (Cambridge: Cambridge University Press, 1997), 52. Although Morris Dancing is still popular today throughout Britain and parts of the United States, the blackfaced "Border Morris" appears to have died out. See E. C. Cawte, "The Morris Dance in Hereford, Shropshire and Worcestershire," Fournal of the English Folk Dance and Song Society 9/4 (1996). 


\section{Music and Politics Summer 2007}

gained popularity around the world as one of the few uniquely American contributions to theater. The centerpiece of the minstrel show was comic routines performed by white men with corkblackened faces. The black mask and the typical rubrics of the minstrel performance clearly suggested a rudely stereotyped characterization of the slave, often supporting what Herbert Holl summarizes as the common white misperception of slave life at the time:

[Northerners imagined] an idealized landscape combined with relaxation, simple, rustic pleasures and the nobility of honest, rewarding labor; all culminating in an enviable and glorified lifestyle. Slave life was actually seen as an ideal one, by viewing the slave as an uncomplicated, child-like creature, happy and lovable, enjoying life's simple pleasures while reaping the satisfactions of honest toil for a beloved 'Massa,' whose kindness swept away all sorrow and care. ${ }^{4}$

The constant jesting, dancing, and singing of nonsense lyric in dialect of the early blackface shows played upon this image. Despite the obvious racially derived context, early minstrelsy focused on larger social issues that may have unified people across racial divides.

Recent scholars such as Eric Lott, Dale Cockrell, William T. Lhamon, and William Mahar have argued that early (pre-1840) minstrelsy was not primarily about slave culture, but about social class. ${ }^{5}$ The shows drew lower-class audiences of all races together for an evening of raucous entertainment that veiled a harsh criticism of the upper classes and American elitism through the auspices of the cork-blackened face:

... its purpose was to display, to criticize, to ridicule, to hold up to nature a cracked mirror showing only a partial reflection of the complexities of antebellum life... ${ }^{6}$

As Lhamon and Cockrell point out, the early shows were entertainment produced by and for the lowest rungs of American society, which included not only blacks, but "Irish, German, French, Welsh, and English recent immigrants, as well as American rustics."

These plays are the first distinctive cultural product of the mixed cohort that industrial metropolises and their imperial plantations were making. Their mixed theatre articulated the overlappings of youth, class, and colonial culture mutating in the Atlantic diaspora. Rice's cohort enacted and instructed the alternate consciousnesses, then start[ed] to give lip to power. ... When Rice jumped Jim Crow, he showed the unsettled autonomy of that agency most feared to the middle class... ${ }^{8}$

4 Herbert Holl, "Some Versions of Pastoral in American Music," Ph.D. dissertation, (University of Texas at Austin, 1980). As quoted by Calvin Elliker, Stephen Foster Guide to Research (New York: Garland Publishing, 1988), 52.

5 Eric Lott, Blackface Minstrelsy and the American Working Class (New York: Oxford University Press, 1993). William T. Lhamon, Raising Cain: Blackface Performance from fim Crow to Hip Hop (Cambridge: Harvard University Press, 2000). William Mahar, Behind the Burnt Cork Mask: Early Blackface Minstrelsy and Antebellum American Popular Culture (Champaign: University of Illinois Press, 1998).

6 Mahar, p. 353. Mahar (p. 347) believes that issues of social class were secondary to a focus on the "pretentiousness that accompanied American elitism."

7 Lhamon, p. 44.

8 Lhamon, p. 211. 
Such important figures as comedian Thomas D. Rice, who is seen by many as the "father of blackface," came from the white lower class and his early acts were presented without "the intermediary of professional writers and composers from the upper classes."

Minstrelsy saw a fundamental change towards the end of the 1830s as Rice and other early minstrels began to see the economic potential of the popular entertainment (and as they, themselves, left the social classes for which the entertainment had been designed). ${ }^{10}$ Indeed, they recognized that they could take advantage of a shifting social landscape as well as the pocketbooks of more well-to-do audiences by refocusing the musical acts on the acceptable racial stereotypes at the time. ${ }^{11}$ Cockrell describes the "surprisingly rapid containment of the social noise of minstrelsy" beginning in 1840:

The texts to blackface songs from 1828-1840 or so are filled with period references to political, economic, moral, and social issues, including the debate over slavery... There is much less chance of this kind of sentiment...by the mid-1840s. Dialect blackface had become by then more a form of gross mockery-of blacks, of women, of the powerful too... ${ }^{12}$

Indeed, according to substantial documentary evidence from the 1840s cited by Mahar, blackface troupes "risked failure" unless they, as described in an article from an 1847 Spirit of the Times, "emphasized delineations of Negro eccentricities" or focused their acts on that which "the legitimate object of their costumes and colored faces, namely the personation of the witty negro." ${ }^{13}$ Minstrel performers of the time were even sure to clarify that the performers were not actual slaves, but whites in costume by including pictures of the performers both in and out of costume on posters and playbills. ${ }^{14}$

It is no coincidence that the northern misconception of slave life (as described by Holl above) arose at a time when slavery was becoming an issue of major controversy. The 1840s minstrel show satisfied the curiosity of the northern white middleclass audience, the majority of whom had had no contact with southern slaves. It was here that blackface minstrelsy was most popular. Before Uncle Tom's Cabin, claims Robert Toll, minstrelsy was the single greatest influence on the northern public's perception of the black slave. ${ }^{15}$ In the north and in Europe, the minstrel show was seen as an accurate portrayal of slave life. Advertisements of the late 1830s proclaimed the authentic content of their productions: "songs, refrains and ditties as sung by the Southern slaves at all their merry meetings such as the gathering in of the cotton and sugar crops, corn huskings, slave weddings, and junketings." 16 The most successful minstrel groups of the time attempted to show that black slaves differed inherently from free, white Americans, perhaps in an effort to ease the 'American conscience.' They emphasized that which they viewed as the 'peculiarities' of the African-American population and even

9 Ibid, p. 211.

10 For more on Rice's enviable financial situation, see Cockrell, pp. 66-68.

11 Cockrell (p. 161) cites the "hiring of agents" as the final step in the transition from early to mature minstrelsy.

12 Cockrell, pp. 146-147

13 Mahar, p. 40. October 16, 1847 Spirit of the Times also quoted in Mahar. Lhamon (p. 246) also discusses the refocusing of minstrelsey on race: "During the era when the racism of the minstrel show was most confining ... the democratic urges of the underclass alliance went into undertow. They diffused back into folklore which was independent of the curated texts of middle-class life."

14 Lott, p. 20

15 Robert C. Toll, 28.

16 Edward Le Roy Rice, Monarchs of Minstrelsy, from "Daddy" Rice to Date (New York: Kenny Publishing, 1911), 24. See also Charles Hamm, Yesterdays: Popular Song in America (New York: Norton, 1979), 231. 


\section{Music and Politics Summer 2007}

described their troupes in exotic ways, calling themselves 'Ethiopian Delineators. ${ }^{17}$ On the other hand, the growing popularity of the genre amongst northerners reflected a political stage ripe for the developing abolitionist movement. Eric Lott describes the contradictory nature of minstrelsy:

$[\mathrm{We}]$ find that blackface performance, the first formal public acknowledgement by whites of black culture, was based on small but significant crimes against settled ideas of racial demarcation...In blackface minstrelsy's audiences there were in fact contradictory racial impulses at work... [Indeed,] minstrel performers often attempted to repress through ridicule the real interest in black cultural practices they nonetheless betrayed... ${ }^{18}$

It is at this critical point in minstrel history that Stephen Foster enters, with a developing musical style that exemplifies this conflict, seeking to balance the marketing potential of his works with a growing abolitionist perspective.

While the music Rice had used for the first shows (to "jump Jim Crow") were essentially simple song outlines that could be filled in by improvised verses and were to be accompanied by Rice's antics, the lucrative sheet music market required professional composers who could create more cohesive and fixed-form songs. ${ }^{19}$ Thus Foster shifted from parlor ballads to the financially advantageous minstrel market, but not without some trepidation. His later adaptation of the "Plantation Melody" suggests that his abolitionist leanings eventually outweighed his fiscal prudence. However, the public's enormous interest in Foster's new style confirmed and reinforced the changing political horizon, wherein the composer, perhaps unwittingly, played an important activist role.

Despite early claims to the contrary, Foster's music bore little resemblance to the slave music of the time. ${ }^{20}$ Several scholars have instead suggested that Foster's work was overwhelmingly influenced by Anglo-Celtic folksong. ${ }^{21}$ This was also true of a number of contemporaneous minstrel composers and may be rooted in a public perception that considered the culture of Irish immigrants to be one that was shared with that of northern blacks. It certainly was not uncommon to hear an Irish brogue or folk song as part of a minstrel show. ${ }^{22}$ Robert Cantwell observed that several derogatory terms of

17 The term 'Ethiopian' was not referring to the actual country of Ethiopia, rather to the Latin term, 'Ethiopia' which for some time was considered synonymous with 'Africa'.

18 Lott, 4-6. Lott goes on to say: "Underwritten by envy as well as repulsion, sympathetic identification as well as fear, the minstrel show continually transgressed the color line even as it made possible the formation of a self-consciously white working class. There was a good fit, for example, between the conflicted nature of the shows and the racial tendencies of their audiences, such that the artisan abolitionist constituency could rather benignly enjoy the same form of leisure that supported racist, antiabolitionist ridicule." (p. 8)

19 Cockrell, pp. 76-79.

20 Stephen Foster's brother Morrison wrote the first published biography of Foster, in which he paints a rather fanciful portrait of the composer "steeped" in what Root (p. 7) calls "the deep faith of mother-worship, family loyalty, and sentiment of the genteel society in late Victorian America." In this biography, he claims that Foster's music was completely authentic in its borrowings from black culture, having learned it from black religious services he attended in Pittsburgh. While some of the relatively limited authentic borrowings may have derived from this source, the anglo-celtic connection is clearly the stronger of the two influences. See Morrison Foster, Biography, Songs and Musical Compositions of Stephen C. Foster (Pittsburgh: Percy F. Smith, 1896). Reprinted as My Brother Stephen (Indianapolis: Josiah K. Lilly, 1932), 49-50.

21 See Otto Gombosi, “Stephen Foster and 'Gregory Walker,” Musical Quarterly 30/2 (1944): 133-146. Also, George Jackson, “Stephen Foster's Debt to American Folk-Song.” Musical Quarterly 22/2 (1936): 154-169.

22 The postulation that minstrelsy not only influenced the northern perception of slave life, but also that of other social classes of the time carries enormous ramifications. Joyce Flynn begins to detangle this notion, stating that "blackface, bizarrely enough, was actually used to represent all ethnicities on the antebellum stage..." In "Melting Plots: Patterns of Racial and Ethnic Amalgamation in American Drama Before Eugene O’Neill,” American Quarterly 38.3 (1986): 426. 
the time referred to both minority groups. In addition, important figures such as Fredrick Douglass and Fanny Kemble noted (somewhat dubious) similarities in cultural practices. ${ }^{23}$

The Anglo-Celtic influence on Foster is particularly evident in the pervasive pentatonicism of the minstrel songs. Although virtually all the minstrel songs emphasize scale-degree five, a great many of them avoid four altogether or use it only as a local neighbor to three. The pentatonic descent from scale-degree 5 makes for a gapped line, never to be truly closed. This may contribute to the sense that the strophes of these songs could simply continue eternally without recourse to a full stepwise descent. Several of the songs at least suggest dominant support for scale-degree four before the return to tonic that supports scale-degree three. In these cases, I have shown the implied fourth scale degree in my graphs. In the other pentatonic songs, the analyst has little choice but to take scale-degree three as a primary tone. ${ }^{24}$ Note that in virtually all cases this leaves five as a cover tone with nearly the same weight as the primary tone. The pentatonic construction of the minstrel songs also produces a paucity of harmonic variety, such that any departure from the tonic and dominant strikes the listener as an especially salient harmonic shift.

Foster's parlor ballads, intended primarily for the home amateur market, show Anglo-Celtic influence as well, but also borrow from contemporaneous Italian arias. Even his first published song, "Open Thy Lattice Love," contains elements of their lyrical style (refer to Examples 1a and 1b). For this song, Foster chose to set a text by George P. Morris. This is rather uncharacteristic for Foster, who always preferred his own meticulously prepared texts. He published the song in 1844 when he was only 18 years old and it is the first in a long line of serene love ballads. The lyrical 6/8 meter and motivic turn figure, which sets the titular phrase, “open thy lattice love," reflect the poem's frequent references to the sea. This strophic song consists of four 4-bar phrases in a quatrain format. The first phrase is governed by a middleground third descent from scale degree 5 (A) to 3 (F\#, m. 4). The second tonicizes $\mathrm{V}$ and continues to prolong $\mathrm{A}$. The first full descent occurs in the third subphrase, but the arrival on the Tonic (D, m. 12), is supported only by vi, in a deceptive cadence. The true descent only appears in the final 4-bar unit, which contains significant elements of the first phrase.

The denial of closure throughout the song mirrors the yearning of the text: "open thy lattice, love, listen to me!" The protagonist is attempting to engage the interest of his beloved, but has not yet been able to attract her attention. The pleading is emphasized by the leap of a sixth at the words "listen to me!” (m.2). The sixth leaps from the fifth of the tonic chord to the third, and the arpeggiation is completed by the arrival of the root on the fourth beat of m. 2. In m. 12 the voice leaps again, this time by an octave from D-D, but still followed by a third down. The text here is "away and away!" or "the waters away!" and emphasizes the fleeting nature of this moment. Again the protagonist is impressing on his beloved to hurry and "open the lattice." This is the moment of the deceptive cadence, accurately representing the obstinance of the beloved as she keeps the protagonist from his

23 Robert Cantwell observes that "smoked Irishman" was rural slang for a black slave in Bluegrass Breakdown: The Making of the Old Southern Sound, (Urbana: University of Illinois Press, 1984), 262. Actress Fanny Kemble wrote in her diary of the remarkable resemblance between the "low Irish" and southern slaves (quoted in Lott, 95). Frederick Douglass remarked that the only songs that came close to the pathos of slave songs were those he had heard in Ireland. In My Bondage and My Freedom [1855], ed. William Andrews (Urbana: University of Illinois Press, 1987), 76.

24 David Carson Berry has suggested that the "gapped urlinie" may be a structural feature of early American popular song, but the pentatonic gaps here seem to suggest a motivic "nostalgia" that would be lost in a normalized urlinie structure. 


\section{Music and Politics Summer 2007}

goal. The A-F\# leap returns in m. 14, again on the words "listen to me!" The placement of the text has been altered, however, so that "me" falls on the apex pitch. The harmony is a secondary dominant to vi, reminiscent of the octave leap with the deceptive cadence. In addition, the third from F\#-D has been filled by a passing tone. Perhaps the protagonist has become so enraptured in his romantic musings that he has forgotten his original goal. This would explain the emphasis on the word "me." The vi chord supports a further stepwise descent from D-C-B, where the harmony becomes a IV6, whose predominant function is thwarted by a return of the primary tone, A, and the tonic chord in m. 15. Although ultimate tonal closure is imminent (this is a popular song of the 1840s, after all), scale degree two does not proceed directly to tonic, but is interrupted by an F\# from the tonic chord (m. 16).

The opening chromatic lower neighbor motive (A-G\#-A) and the related upper neighbor motive (A-B-A) together produce a full turn figure, itself motivic and representative of the titular phrase, "open thy lattice love." Several instances of the motives occur in the second 4-bar unit (mm. 5-8) and are marked in the graph. The opening motion of the phrase is A-G\#-A, but within this is embedded an additional lower neighbor to $\mathrm{G} \#$. The first three bars of the phrase, in fact, consist of a stepwise linear ascent from G\#-C\# moving with alternating fifths and tenths in the bass. Each pitch of the ascent is itself decorated by one of the two neighbor motives. The complete turn figure appears in mm. 6-7 (C\#-D-C\#-B-C\#) and is reduced to a double neighbor in m. 8 (A-B-G\#-A). The opening turn figure is reversed in the final phrase (mm. 13-14), so that the A-G\#-A neighbor appears with the text "listen to me," tying the protagonist's imploration with the titular phrase. The alteration of the text-music placement again emphasizes the urgency of the "listen to me" and also supports the perception that the protagonist's original goal, “open thy lattice love," has actually been replaced. ${ }^{25}$ Foster's ballad style commonly employs this type of sophisticated motivic structuring.

The faint chromaticism and bel canto lyricism overwhelms the pentatonic suggestions in "Open Thy Lattice Love," but they live in uneasy coexistence in another early ballad "Ah, May the Red Rose Live Always," published in 1850 (Example 2). The Italianate decoration mm.3-4 acts in stark contrast to the pentatonic Anglo-Celtic of mm. 1-2. Here we get a strong taste of the quintessential Foster "nostalgia," the ever-returning theme of his later songs. The influence of Thomas Moore's Irish Melodies, a very popular collection of songs published between 1807 and 1835, with which Foster would have been well acquainted, is especially evident. ${ }^{26}$ It is in Moore's songs that we can find the inspirations for Foster's ballad and later minstrel styles. As in much of Moore's poetry, the text of "Ah, May the Red Rose Live Always" turns quickly to subjects far from the actual love of the protagonist. In fact, the distance placed between the singer and his beloved in all the early ballads suggests an almost antiseptic environment, especially when compared with the raucous nature of Foster's first minstrel song, "Lou'siana Belle."

See "The Structural Roles of Pentatonicism in Tin Pan Alley Songs" 2003 (November), annual national conference, Society for Music Theory (Madison, WI).

25 The formal process used here suggests a chiasmus wherein a dialectical reversal takes place around a transformational center. The form is commonly used by 19th century art-song composers and often suggests an isolation of the idealistic "frauenbild" as a projection of the protagonist's imagination (see, for example, Schubert's "Der Fischer").

26 See Hamm (1979), 205. 
Foster wrote "Lou'siana Belle" in 1845 for the delight of his three closest friends, one of whom was the poet Charles Shiras, who will be discussed later. Published in 1847, it was structured like all the early minstrel songs, including pentatonically-organized melody with a restricted range and simple diatonic harmony. Written in heavy dialect, which was based more on white convention than on actual slave speech, the text depicts a slave attempting to woo the white master's favorite black mistress, saying "Oh! Belle...don’t tell Massa...I's guine to marry you.” As mentioned by the text in the second strophe ("I danc'd de Polka pigeonwing") the meter is a lively $2 / 4$ polka, a dance that had only arrived in the United States a year before the song's composition. Although it may be difficult to imagine, the polka was associated with debauchery and was quickly appropriated by blackface composers to reflect their portrayal of the "uncivilized" slave. ${ }^{27}$ This is supported by the original performance marking, which includes a racial epithet. ${ }^{28}$

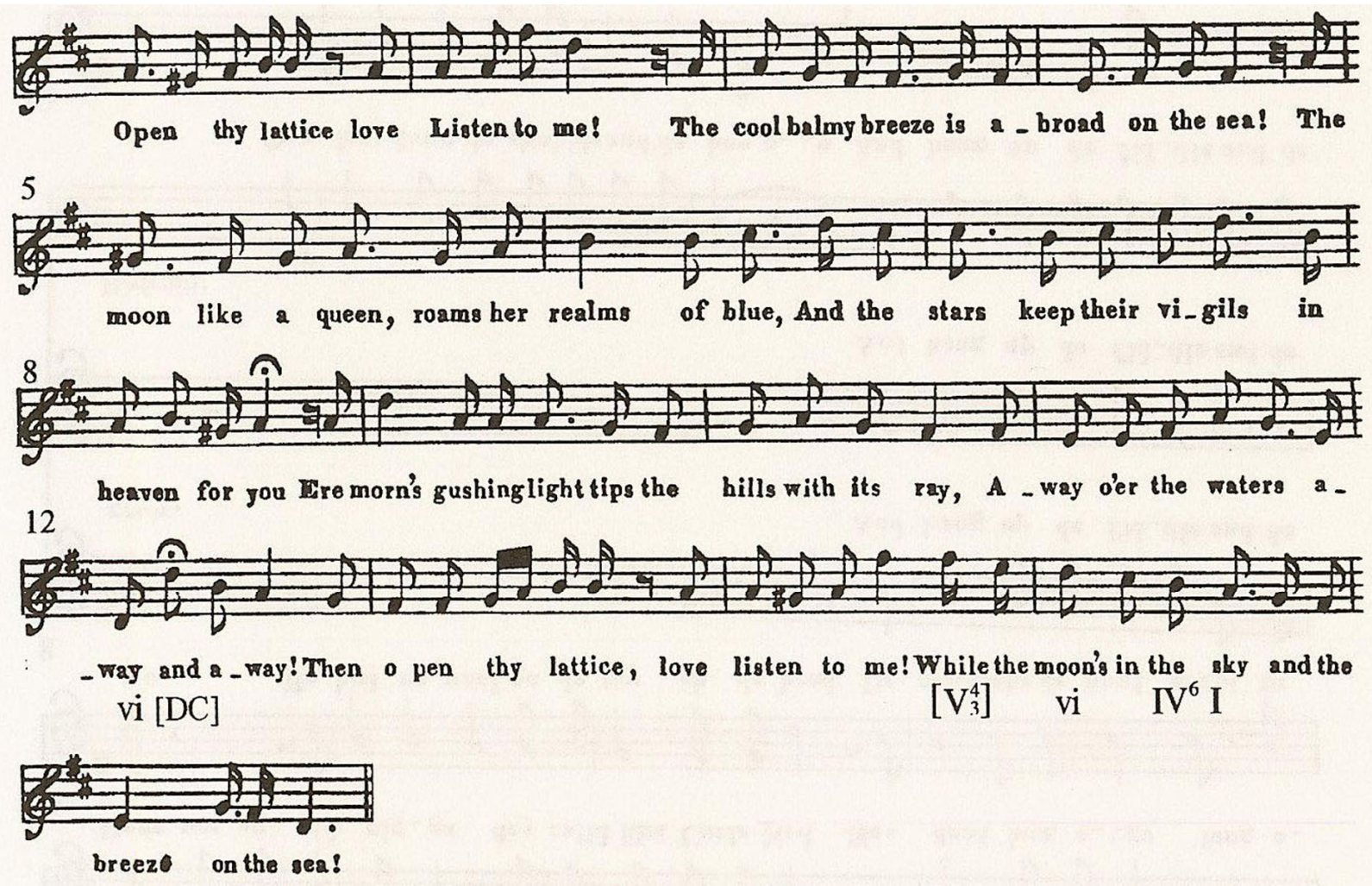

Example 1a: "Open Thy Lattice Love” (1844), verse 1

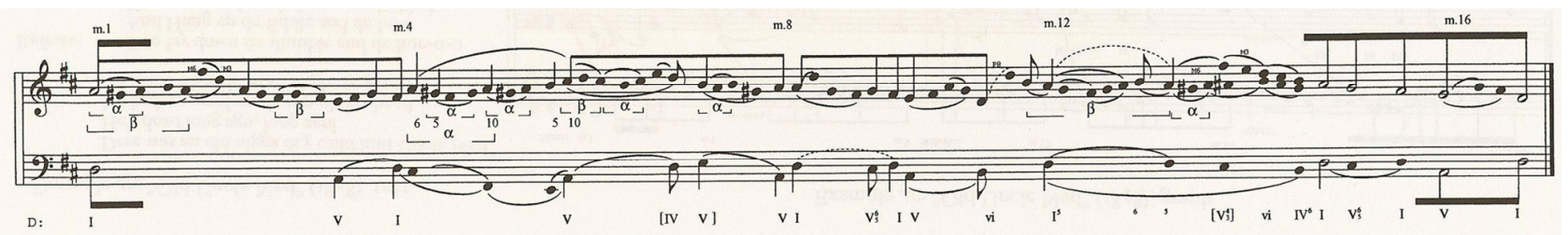

Example 1b: "Open Thy Lattice Love" (1844), graph

27 Ken Emerson, Doo-dah!: Stephen Foster and the Rise of American Popular Culture (New York: Simon and Schuster, 1997), 105.

28 "alla niggerando [sic]" 


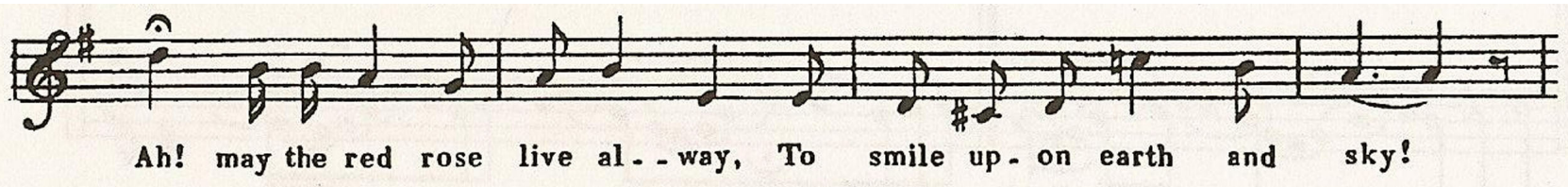

Example 2: “Ah! May the Red Rose Live Always” (1850), verse 1, mm. 1-4

Like “Open Thy Lattice Love," this song includes two eight-bar periods, the first of which is the strophic verse, while the second is the repeated refrain (see Examples $3 \mathrm{a}$ and $3 \mathrm{~b}$ ). Foster juxtaposes the ascent of the verse with the descent of the first half of the refrain. The climax occurs in the second subphrase of the refrain, when the melody reaches its apex pitch and the rhythmic values accelerate to highlight the protagonist's declaration, "I's guine to marry you." The verse's opening arpeggiation to the A primary tone and its subsequent prolongation through a B upper neighbor reflect the pentatonically-organized melody. In fact, both of these features appear repeatedly in Foster's minstrel works, even to the extent that the neighbor B is supported by a non-structural subdominant in the bass. The limited harmonic motion highlights another structural feature common among the minstrel works. It is not unusual for scale-degrees four, three, and two to be supported by a single dominant harmony, as they are in both verse and refrain. The missing predominant is subsumed by the dominant, as its seventh travels through the cadential 6 th of the $6 / 4$ chord, creating 7-6-5 passing motion above the bass. The rhythmic performance of these songs would have compensated, at least in part, for the static harmonic structure.

Although this song is consistent with minstrel treatment of slave subjects, an additional verse that only appears in a Foster manuscript deserves examination (see Example 3c). ${ }^{29}$ Even in this extremely early song Foster considers a verse that departs from the contemporaneous minstrel tradition. The suggestion that the selling of a slave by a master could cause any pain was probably too radical for the young and insecure Foster to include in the published version. The final printed verse of his second minstrel song, however, hints at the same uneasiness with the prevailing approach to blackface texts.

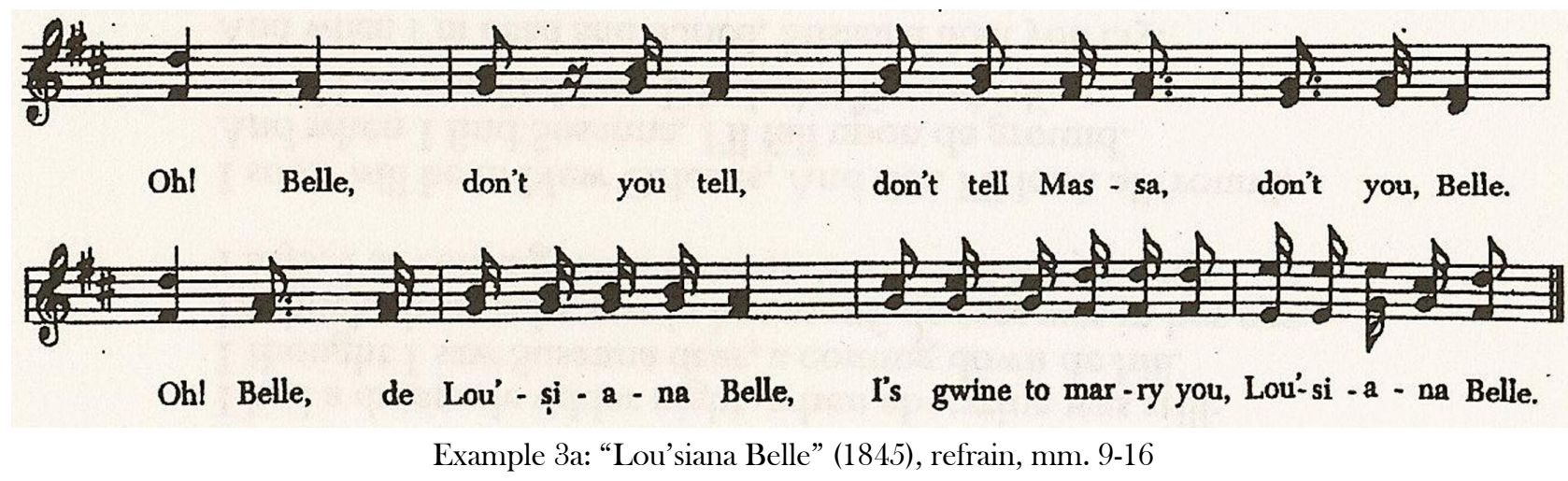

29 John Spitzer, “'Oh Susanna': Oral Transmission and Tune Transformation,” Journal of the American Musicological Society 47.1 (1994): 110, n. 42. 


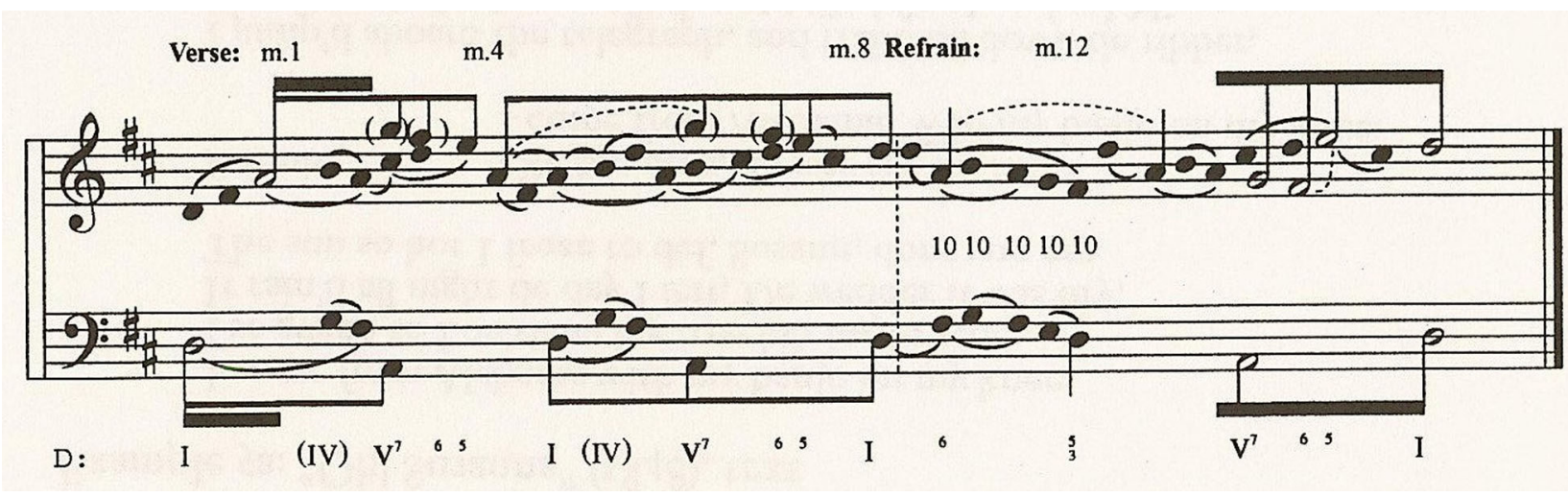

Example 3b: "Lou'siana Belle” (1845), graph

My masa took my lub one day, He put her up to sell, I thought I's pine my life away, for de Lousiana belle.

Example 3c: "Lou'siana Belle" (1845), original verse from manuscript

Foster completed "Old Uncle Ned" only a short time after "Lou'siana Belle" (1848), but here we find a song of much greater substance. Although the first two verses written by Foster follow the minstrel stereotypes in their characterization of the black slave, the third verse and the refrain strike a surprisingly different tone (see Example 4a). Here, death will relieve Ned from the "hard work" of slave life. In addition, Ned will actually be missed by the plantation owners, so much so that they cry at his passing. A number of features in the music give weight to these aspects of the text.

Dere was an old nigga dey calld him Uncle Ned

He's dead long ago, long ago!

He had no wool on de top ob his head,

De place whar de wool ought to grow.

Refrain: Den lay down de shubble and de hoe-0-0

And Hang up de fiddle and de bow.

No more hard work for poor old Ned,

He's gone whar de good niggas go.

His fingers were long like de cane in de brake,

He had no eyes for to see,

He had no teeffe to eat de oae cake,

Se he had to luf dat oae cake be.

When Old Ned die Massa take it mighty bad,

De tears run down like de rain;

Old Missus turn pale, and she ges berry sad

Cayse she nebber see Old Ned again.

Example 4a: "Old Uncle Ned” (1848), text 
Like "Lou'siana Belle," “Old Uncle Ned” includes an ascent to the scale-degree 5 primary tone and a neighbor subdominant chord, which control the harmonic and melodic motion of the first phrase. In addition, both songs share similar phrase structures: a single 8-bar period for the verse and a refrain that consists of four measures of new material and a four-measure varied repeat of the verse's consequent. In "Uncle Ned," however, these processes are explored and embellished in significant fashion.

The initial ascent to the primary tone is spread over two measures and includes consonant support (albeit weak) for scale degree four. When the voice arrives on the primary tone in $\mathrm{m} .2$, it immediately drops down a fifth, back to the tonic, mirroring Uncle Ned's difficult life as a slave and the finality of his death. ${ }^{30}$ Foster varies this material in the second part of the refrain (mm. 13-14), setting the text "no more hard work for poor old Ned." Here, however, the ascent slips past the Dprimary tone to an $\mathrm{E}$ neighbor, passing through a rare chromatic passing tone. The chromatic ascent and its parallel tenths in the bass certainly underscore the difficulty of the work Ned has done throughout his life. The fermata and predominant support of the E, however, suspends the drama until the change in register and cadence suggest that there may be peace for Ned in his passing. Foster makes this even more dramatic by immediately repeating the final phrase with an embellishment of the melody. Each pitch of the ascent is itself decorated with the motivic ascending third found in the initial ascent of the song. This type of formal expansion is so rare within the minstrel repertoire that its use here seems particularly noteworthy.

Two other details of the song suggest that Foster may have been attempting a more accurate picture of slave life and culture. First, the andantino performance marking stands in marked opposition to that of "Lou'siana Belle." Second, the call-and-response organization of the refrain may indicate an effort to replicate or at least recall African-American song. ${ }^{31}$ This is particularly significant for a composer who would probably never see a "cane brake" and certainly would have had little opportunity to hear live examples of call-and-response. The call consists of a bass voice reciting "den lay down de shubble and de hoe-o-o," starting on the D primary tone, then replicating the fundamental descent on the word "hoe." This is the only phrase in the song that does not start with an ascent to the primary tone. In fact, the final pitch of "hoe," $\mathrm{B}$, leads the descent in the top voice when it enters with the response. The lack of any ascent may reflect the text in which Ned is putting down his tools and his instruments. Indeed, there is no work to be done in this phrase.

30 This interpretation is suggested in Emerson, p. 109.

31 Foster may simply have tried to copy a source that he would have seen as more authentic than the music of contemporaneous minstrel composers: the popular hymnody of the Hutchinson Family Singers. 

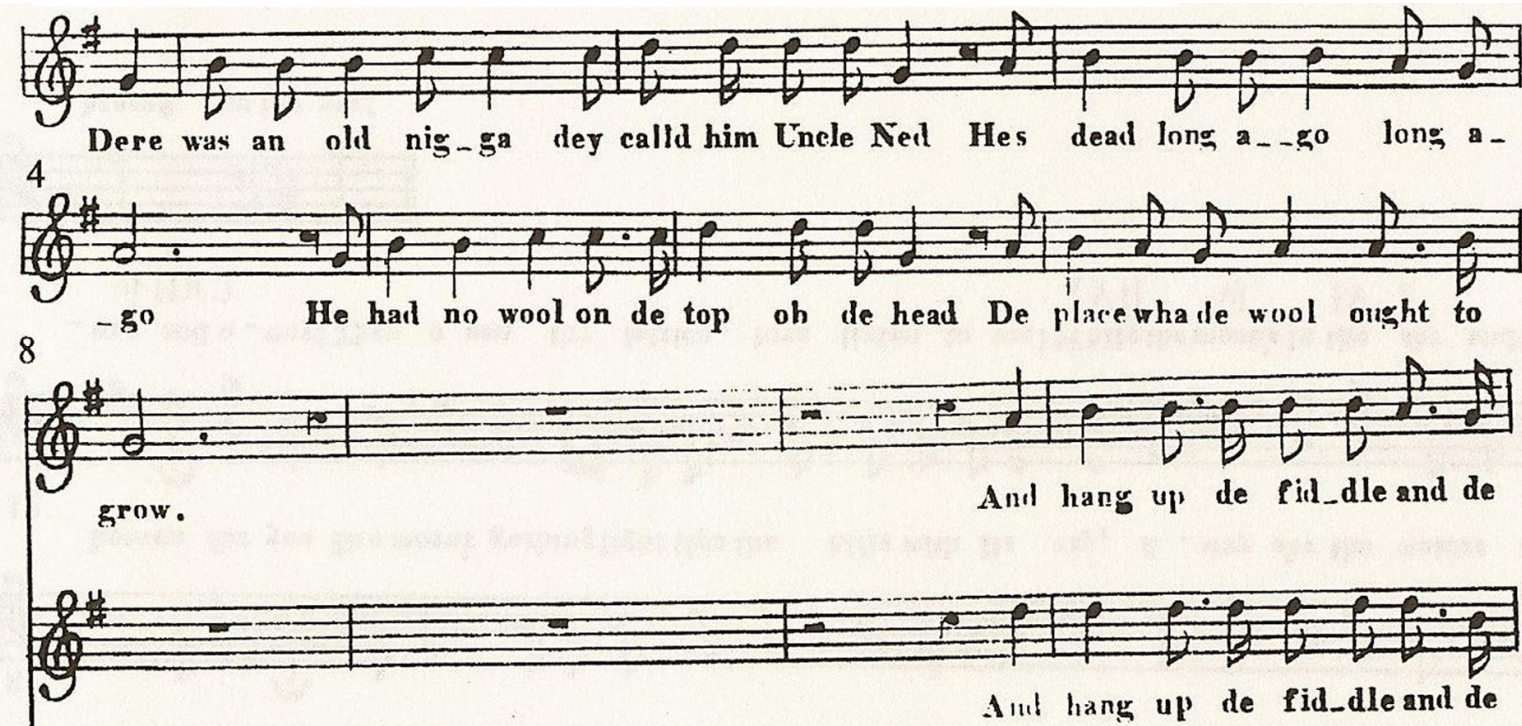

Refrain:

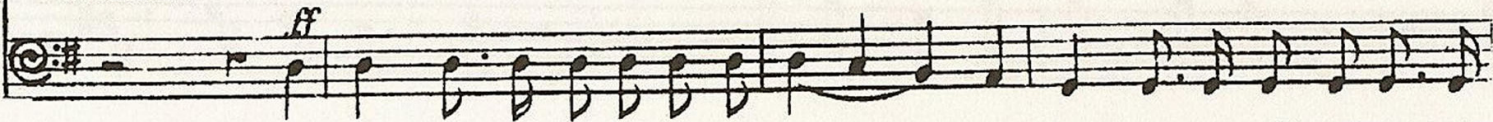

Den lay down de shuhbleand de hoe_o_ o And hang up de fil_dle and de

12

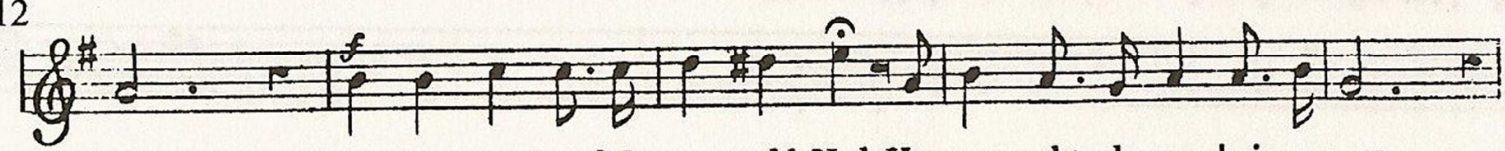

17

No more hardworkfor poor old Ned Hes gone wha de gool nig gas go"

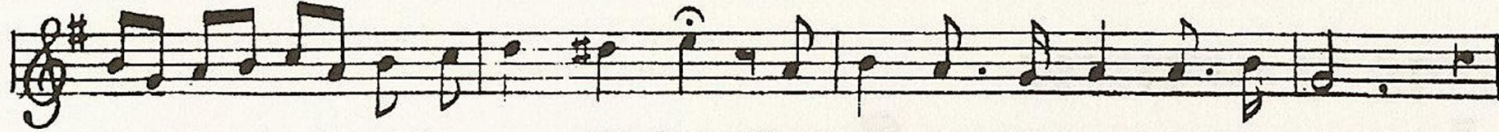

Ni more hard wor for prour old Ned Hes gnne wha de good nig-gas go.

Example 4b: "Old Uncle Ned" (1848), verse and refrain

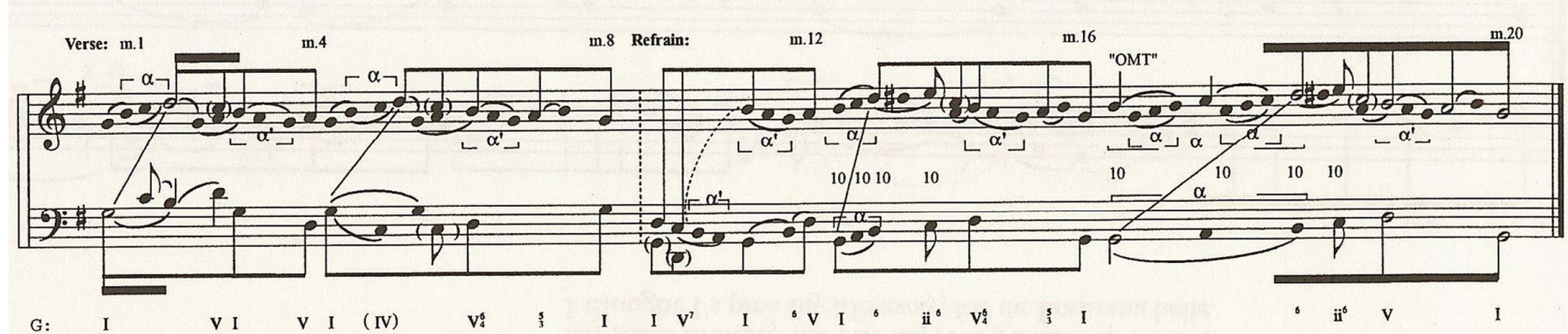

Example 4c: "Old Uncle Ned” (1848), graph 
Foster's "Oh! Susanna” follows the minstrel stereotype more closely than the two earlier songs, defining the slave as simple and dim-witted. This may be why it quickly became a mainstay of the blackface minstrel show, after its publication in 1848. Most Americans (and many non-Americans) could sing at least one verse of "Oh! Susanna," but fortunately almost no one remembers the particularly grotesque second verse (see Example 5a). ${ }^{32}$ This song involves a romantic quest that no African-American man could have undertaken, not only because of the freedom required to travel, but also because the protagonist would be traveling north from Alabama to New Orleans. The nonsense of lyrics such as, "It rain'd all night de day I left, De wedder it was dry, The sun so hot I froze to def," characterizes the protagonist as naive and unsophisticated. The second verse describes a frantic ride that includes cutting-edge technology-from the telegraph, which was also the name of a well-known steamboat, to the train, the engine for which was sometimes called a "bulgine" (wherein the singer confuses the "horse power" for an actual horse). ${ }^{33}$ The minstrel audience would have immediately understood the plays on words, taking delight in the singer's confusion of new technologies.

I come from Alabama with my banjo on my knee;

I'se gwine to Lou'siana my true lub for to see.

It rain'd all night de day I left, De wedder it was dry,

The sun so hot I froze to def, Susann, dont you cry.

Refrain: Oh! Susanna, do not cry for me;

I come from Alabama, Wid my banjo on my knee.

I jump'd aboard the telegraph, and trabbled down de ribber, De lectricik fluid magnified, and killed five hundred Nigga.

De bulgine bust and de hoss run off, I really thought I'd die'

I shut my eyes to hold my bref, Susanna, dont you cry.

I had a dream de udder night, when eberyting was still;

I thought I saw Susanna dear, a coming down de hill.

De buckwheat cake war in her mouf, de tear was in her eye;

I says, I'se coming from de souf, Susanna dont you cry.

I soon will be in New Orleans, And den I'll look all 'round, And when I find Susanna, I'll fall upon de ground.

But if I do not find her, Dis darkie'll surely die,

And when I'm dead and buried, Susanna dont you cry.

Example 5a: “Oh! Susanna” (1848), text

32 All examples taken from a facsimile of the first edition in either: Stephen Foster Song Book (New York: Dover Publications, 1974). Or The Music of Stephen Foster (Washington: Smithsonian Press, 1990). Not all the verses appear in both editions. This version can be found in the 25 February 1948 edition, published by C. Holt, Jr. in New York.

33 The term "bulgine" is used to describe the engine of a train in Irish sea shanties and in minstrel songs such as, "Wake up, Jake," and "Clear the Track, Let The Bulgine Run" (sometimes known as "Eliza Lee"). 


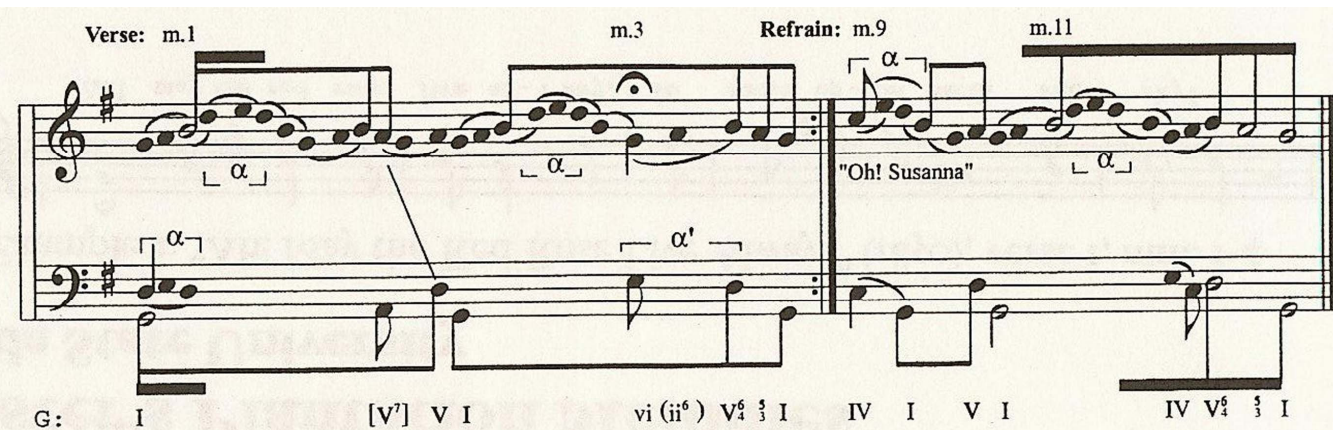

Example 5b: “Oh! Susanna” (1848), graph

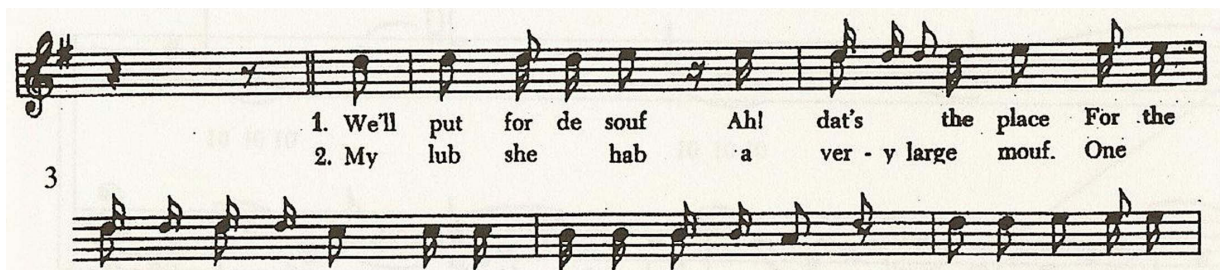

stee - ple - chase and de bul - ly hoss race- Po - ker, brag, eu - cher, cor-ner in de norf, tud-der cor-ner in de souf; It am so long, it

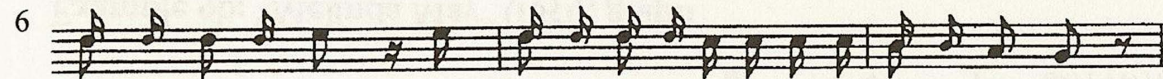
sev - en up and loo, Den chime in dar-kies won't you come a -long too.

reach so far- $\quad$ Trab -ble all a round it on a rail - road car

9 Chorus
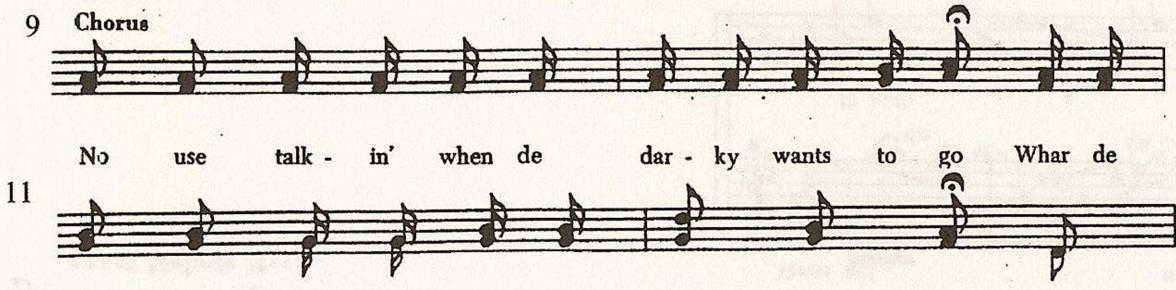

- top . blos - som and de brow; Den

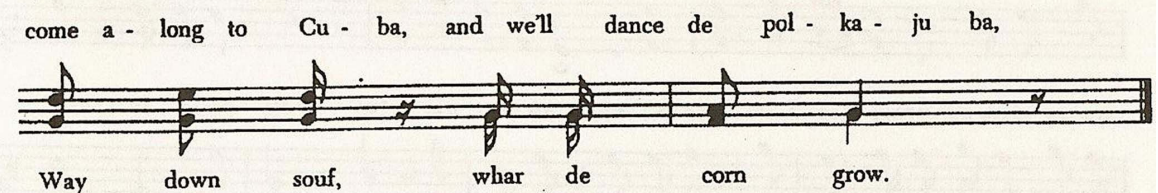

Example 6a: "Away down Souf" (1848), verse and refrain

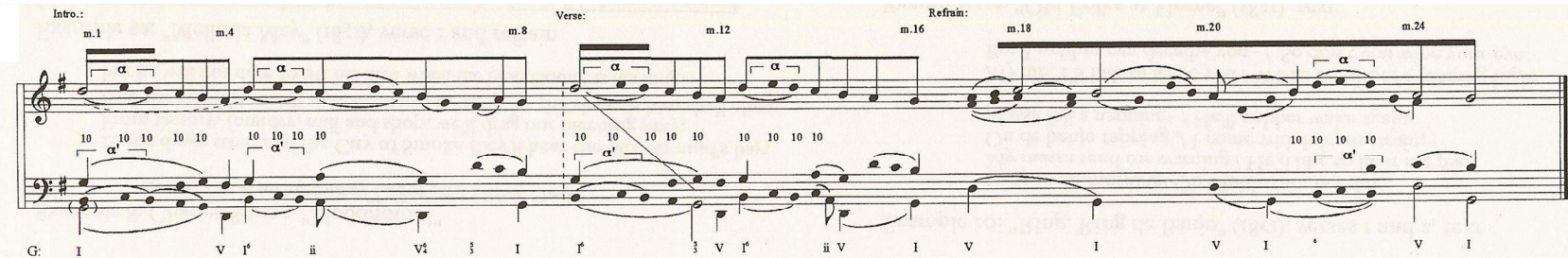

Example 6b: "Away down Souf” (1848), verse and refrain 
The verse of "Oh! Susanna" is completely pentatonic and includes a linear ascent to the primary tone, as in the earlier songs. Here, scale-degree three must act as primary tone, due to the lack of scale degree four in the descent. ${ }^{34}$ The motion between the $\mathrm{B}$ primary tone and scale degree five is significant, however, as the song freely leaps between the two, even decorating $\mathrm{D}$ with a motivic neighbor tone. The gapped scale, dotted rhythms, and quick tempo give this song a sense of restlessness, mirroring the text's tendency to jump quickly between topics.

Foster gives the refrain special emphasis by starting it on the previously missing fourth scale degree and elongating the rhythm on "Oh! Susanna." This is an expansion of the D-E-D neighbor motive from the verse, but its focus on the subdominant sets the protagonist's beloved completely apart from the frantic life of the singer. Indeed, it recalls "Open Thy Lattice Love" in its shift of focus away from the unreachable beloved to the life and fantasies of the protagonist. The isolation of the singer from his lover serves a different purpose in "Oh! Susanna," however. It suggests that a slave couldn't possibly have a significant romantic relationship. The music counteracts any aspect of the text that might allow the listener to take the singer seriously.

"Away down Souf" (1848) projects a similar image of the black slave, while including a crude physical description in the second verse (see Example 6a). In addition to employing the same dialect and harmonic vocabulary as "Oh! Susanna," the song borrows the simple formal strategy from "Lou'siana Belle," with its two 8-bar phrases. Its linear structure is characterized by repeated descents in parallel tenths with the bass (see Example 6b). Only the beginning of the refrain presents a change in motion to a foreground ascent to $\mathrm{C \#} \mathrm{(m.} \mathrm{18).} \mathrm{This} \mathrm{ascending} \mathrm{motion} \mathrm{foreshadows} \mathrm{the} \mathrm{linear}$ structures in the bridges of popular songs over the century following the composition of "Away down Souf.” The C\# here, however, simply continues a large-scale descent of the fundamental line, which closes with virtually no deviations. The motivic structure is equally simple, opening with a D-E-D neighbor embellishment of the primary tone (mm. 1-2). The motive returns at the opening of both the antecedent and consequent in the verse (mm. 9-10, 13-14), and closes the song in the penultimate measure, calling attention, along with the framing rests, to the titular line "Way down souf." The overall structure of the song is especially striking when compared to the non-minstrel songs that Foster was writing during the same period. For example, compare this with "Open Thy Lattice Love," discussed earlier. This type of song reflected and reinforced the racist views embodied by the early minstrel show.

At the end of the decade, Foster began to introduce humanizing qualities into his slave characters, much as he had first attempted in "Uncle Ned." This stylistic shift was also marked by a move towards greater musical complexity and a borrowing from his ballad style. "Nelly was a Lady" (July 1849) is a lament of a slave for his loved one (Example 7a). Although this song still uses dialect and, like all of Foster's previous minstrel songs, was published under the classification "Ethiopian Melody," the protagonist is fundamentally different; a slave who can feel love and sorrow. For the first time in his minstrel music, one finds expanded use of chromatic passing tones, appoggiaturas (see, for

34 A printed version of the song from 1848 reflects the simple nature of the protagonist, restricting the harmonies to tonic, subdominant, and dominant, but Example $5 \mathrm{~b}$ graphs a version published in the same year with a significantly enhanced harmonic vocabulary. It is unclear which of the versions Foster preferred. 
example, the very first pitch of the piano introduction), a slow tempo, and relatively sophisticated extra-musical references such as the dotted funeral motif setting the words, "Toll de bell" in m. 15 .

Foster used a 12-bar A A B form, relying largely on the pitches of the pentatonic scale for the melody, but the song's linear and motivic structure is more complex than such songs as "Away down Souf" and "Oh! Susanna." The piano introduction opens with an F\#-E incomplete neighbor in the right hand, departing from the strategy of the earlier minstrel songs wherein a portion of the verse of refrain serves as piano introduction. This figure becomes motivic, appearing on the surface (mm. 6, 10, 18-19) as well as in several middleground locations (motive alpha in Example 7b). Both the verse and the refrain open with three-bar ascents to the primary tone, $\mathrm{C \#}$. These ascents recall the hardworking life of "poor old Uncle Ned," but here they are given significantly greater weight through their decoration and harmonic support. The piano postlude (also a surprising feature for a minstrel song) includes local chromatic diminutions that clearly reflect the serious tone of the song and includes a salient occurrence of the F\#-E motive, recalling mm. 6 and 10 of the verse.

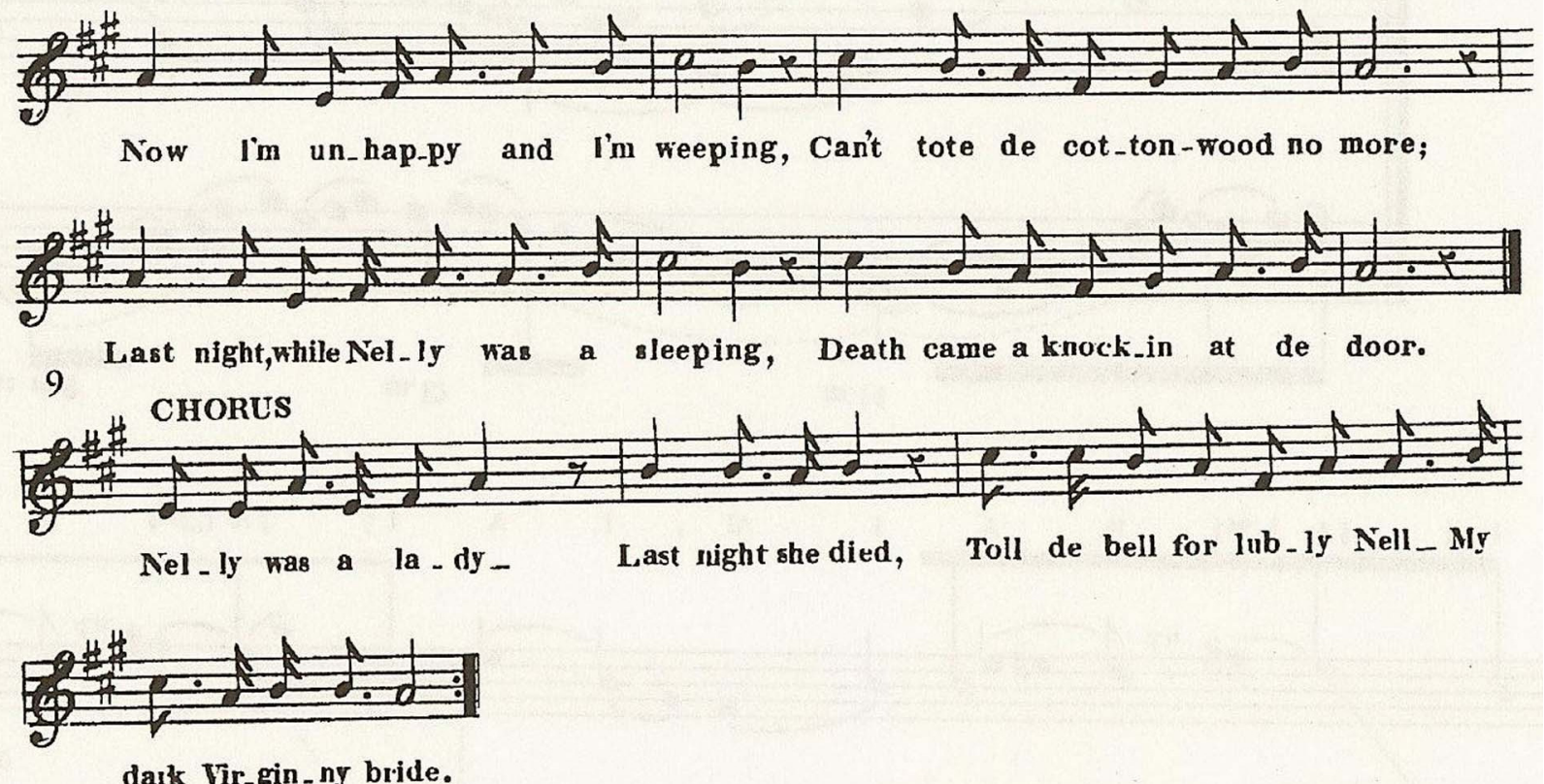

Example 7a: "Nelly Was a Lady" (1849), verse 2 and refrain

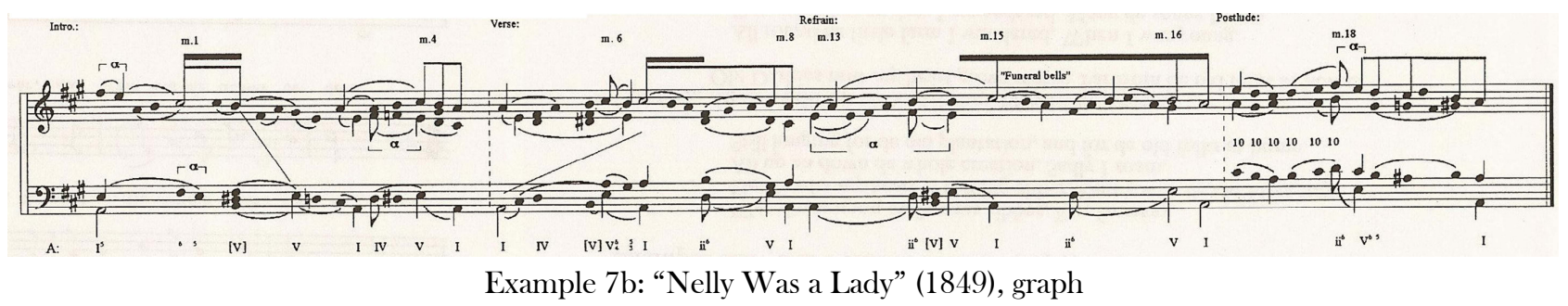


"Nelly was a Lady" marks an important milestone in Foster's minstrel style with its radical suggestion of an African-American "Lady" and its heavy borrowings from the parlor ballads. In his book, "Doo-dah!,” Ken Emerson highlights the significance of this moment in Foster's career:

By merging the minstrel ditty with the parlor ballad, he not only overcame and resolved some of his own musical ambivalence and conflict... he also reconciled black and white, rescuing blackface from the overt racism that had characterized it from the outset. ${ }^{35}$

This shift in Foster's style reflects a changing racial attitude and may have been precipitated or enhanced by several events. In 1850 Congress passed the Fugitive Slave Law, permitting slave owners to send bounty hunters or "slave catchers" to the north to recuperate run-away slaves. This led to numerous demonstrations in Foster's home city of Pittsburgh and put new emphasis on the plight of African Americans. Charles Shiras (1824-1854), one of Foster's closest friends and an abolitionist poet, wrote a poem entitled "Bloodhound" in reaction (see Example 8). ${ }^{36}$ Shiras paints a frightening picture wherein the slave catchers run violently through Pittsburgh (the City of Smoke).

In the dingy streets of the City of Smoke they'll hear the bloodhound's bay; From factory, foundry, mill and shop, we'll drag our bleeding prey;

And the stalwart smith shall his hammer drop, as the slave to him shall cling, For he will not dare to lift his arm when the bloodhound is his king!

Example 8: Charles Shiraz, "Bloodhound” from The Redemption of Labor and Other Poems

In 1847 Shiras started an abolitionist journal, the Albatross. While the journal only lasted a few months, Shiras remained an anti-slavery activist until his death from consumption in 1854. It seems likely that the poet had long preached to Foster about the injustices of slavery, but the new law may have helped him to secure Foster's sympathies. ${ }^{37}$ This is corroborated by a reactivation of their friendship at that time including collaborations on a song entitled "Annie My Own Love" and a play, "The Invisible Prince," in $1853 .^{38}$ A short time after Shiras's death, Foster wrote music for a show commonly called "The Abolition Show," indicating that by then Shiras's influence had had the desired effect.

Foster's first and only trip to the south my also have played a role. Two years after their marriage in 1850, Jane and Stephen Foster took a steamboat to New Orleans. It seems likely that during this trip Foster was able to see slaves working on the plantations. Perhaps this was a rude awakening for him or it simply reinforced his earlier misgivings about the minstrel songs. Whatever the case, one can speculate that this trip brought him to a new realization about the nature of slavery.

Finally, although Foster was raised in a staunchly democratic family with important political ties (Stephen's father served on the state legislature, and his sister had married into the family of James Buchanan, the last Democratic president before the Civil War), the family clearly supported states'

35 Emerson, p. 147.

36 Charles Shiras, The Redemption of Labor and Other Poems (Pittsburgh, 1852), 67.

37 John Burt, "Poet of the Iron City: Charles P. Shiras (1824-1854)," Carnegie Magazine 67.7 (1987): 20-25.

38 Ibid. 
rights and, at least tacitly, the institution of slavery. Stephen's new spouse, Jane, on the other hand, came from a family with a very different political bent. Indeed, her father, Dr. Andrew McDowell had sponsored and supported one of Harvard's first black medical students, Martin Delaney. Perhaps Jane's abolitionist-minded family also played a role in their son-in-law's revised abolitionist leanings. ${ }^{39}$

These events appear to have had such an effect on Foster that he stopped writing minstrel songs altogether, focusing exclusively on parlor ballads. For most of 1850, the minstrel scene saw no new Foster publications, even though he wrote 14 ballads during this period. Unfortunately, the ballads brought in very few royalties, so early in 1851, he composed a "new" kind of minstrel song; a parlor ballad published under the "Ethiopian Song" rubric. The song was "Melinda May." ${ }^{40}$

"Melinda May" is Foster's first song to use no dialect other than the substitution of 'th' and ' $\mathrm{v}$ ' and it is certainly one of the most intricate songs of the minstrel genre. Its leaps, melodic embellishments, appoggiaturas, and chromaticism suggest the same Italian influences as his parlor ballads. This is a love song much like "Nelly was a Lady," and it is quite humanizing:

Lubly Melinda, come now my dear, I'm waiting, I'm waiting for you. Shut down de window, dry up de tear, And walk wid me ober de dew.

Refrain: Lubly Melinda, my sweet Melinda May! I could work in de field, and be happy all de day, If you would only smile again,

My sweet Melinda May.

Here, the singer states that he could even endure being a slave if only his beloved would smile once more. Foster employs an unusually elaborate formal scheme, a a' b c, and distinguishes it from the other minstrel works through the use of secondary harmonies and register transfers (see Example 9b). In addition, this song departs from the repetitive strategies of earlier ones, with a constant variation of the material from the first four measures. Note also that "Melinda May" is the only Foster minstrel song with a background interruption before the refrain. When the consequent of the first phrase returns in the refrain (m. 12), the register transfer from F\#-E (originally seen in mm. 4-6) becomes a full-octave coupling, with the high $\mathrm{F} \#$ supported by a $\mathrm{V}$ of vi. As in the refrain of "Uncle Ned" the stepwise ascent from F\# to F\# consists of an expansion of the opening arpeggiation, emphasizing the text, "happy all de day" and tying it to the earlier occurrence of the apex F\# on "Lubly Melinda." The compositional paradigms borrowed from the ballad style clearly demonstrate Foster's changed conception of the minstrel song and the African Americans therein represented.

39 Root, pp. 8-9. Root argues that Jane was a great source of angst for Foster's family.

40 For details on the royalties that Foster received, see Hamm (1979), 483-484. 


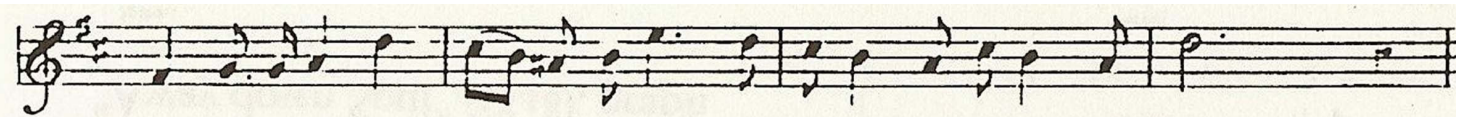

l.uls-l: Melin-da, come uon mydear, I'm saiting. I'm waiting for gou.

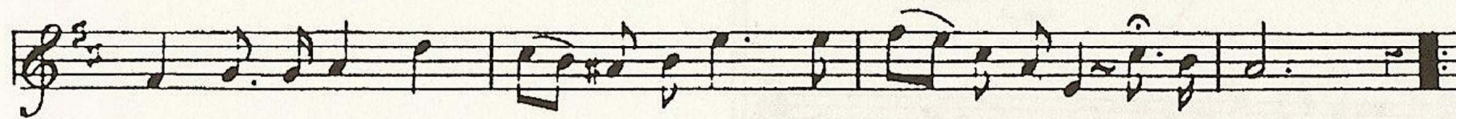

Shut downde win-dow, dry up detear, And watk wid me o-ber de dew.

Refrain (mm.9-16):
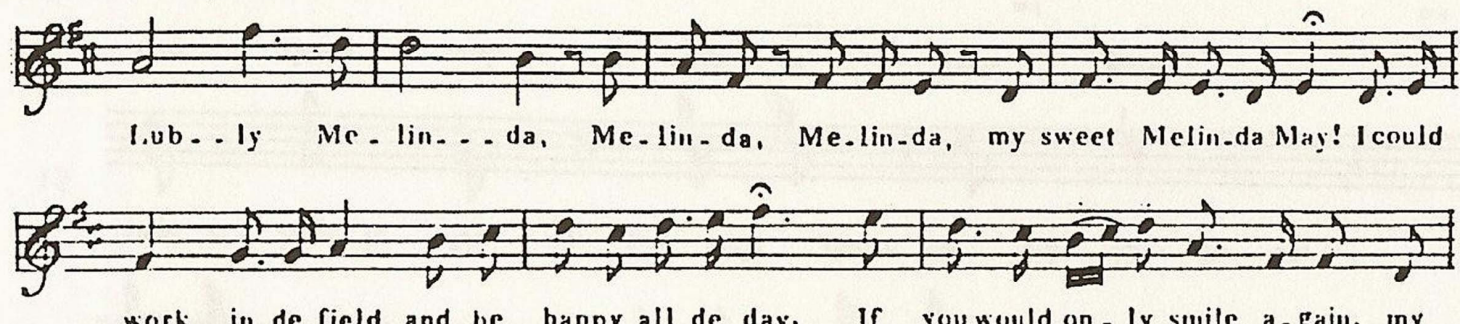

work in de field and be happy all de day, If yourould on-ly smile a-gain, my

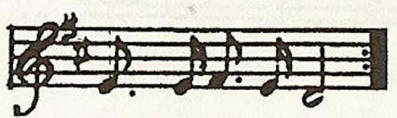

sweet Melinda May.

Example 9a: "Melinda May" (1851), verse 1 and refrain

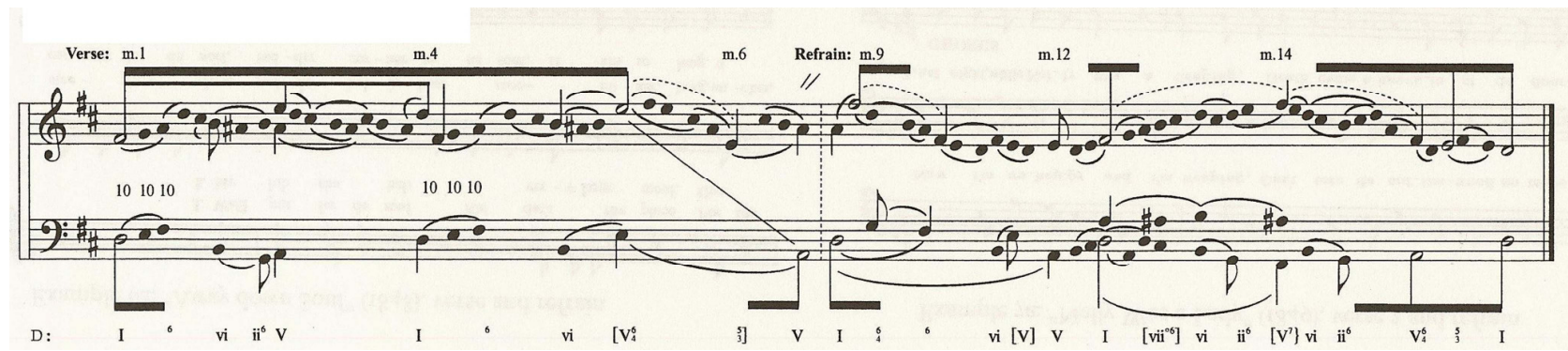

Example 9b: "Melinda May" (1851), graph

Early in de morning/ Ob a lubly summer day,

My massa send me warning / He'd like to hear me play.

On de banjo tapping ,/ I come wid dulcem strain;

Massa fall a napping- / He’ll nebber wake again.

My lub, I'll hab to leabe you / While de ribber's running high:

But I nebber can deceibe you- / So don't you wipe your eye.

Example 10: "Ring, Ring de Banjo" (1851), verses 1 and 2, text 
This may be even more pronounced in the text of "Ring, Ring de Banjo," published only three months after "Melinda May." Although the pentatonic melody, polka rhythms, and three-harmony setting is reminiscent of "Oh! Susanna," a not-so-latent violence is stunningly new (Example 10). In this song, a slave gains his freedom, but returns to the plantation. The possibility that the protagonist bludgeoned his master with the banjo after lulling him to sleep certainly changes one's perception of the rousing chorus: "Ring, ring de banjo!"

Not surprisingly, "Ring, Ring de Banjo" was a failure on the minstrel stage. Indeed, royalties for all the songs of this period were dismal. The public was not yet prepared for this type of activist statement. Growing evermore concerned about his diminishing funds, Foster was forced to write a minstrel tune in the older "musical" style, while still attempting to incorporate his revised view of slavery. The result was his most famous song ever, "Old Folks at Home." Due to his misgivings about returning to the minstrel song genre, however, he allowed the leader of the Christy Minstrels to attach his name to the song, and Christy's name stayed on the song until the renewal of the copyrights long after Foster's death.

"Old Folks at Home" differed significantly from the earlier minstrel songs. Here Foster found a new formula that would capture the public's interest. The key to the success of this era's songs was a sense of nostalgia that traversed racial boundaries (see Example 11a). Despite the light dialect, only the word "darkies" in the refrain gives any true indication that the protagonist might be a slave. While working on the manuscript, Foster hit an important turning point when he changed the word "blacks" to "folks" in the line "Dere's where de old folks stay." At this moment he created a text that could speak to everyone. Foster never saw the Suwannee river that rises in the Okefenokee Swamp, but simply preferred the euphonious quality of its name to that of the Pee Dee river, which he had originally written. ${ }^{42}$ In truth, Foster invites the listener to 'fill in the blank,' for the river is one of the listener's own imagination.

Way down upon de Swanee ribber, Far, far away,

Dere's wha my heart is turning ebber, Dere's wha de old folks stay.

All up an down de whole creation, Sadly I roam,

Still longing for de old plantation, and for de old folks at home.

Refrain: All de world am sad and dreary, Ebrywhere I roam,

Oh! Darkies how my heart grows weary, Far from de old folks at home.

All round de little farm I wandered, When I was young,

Den many happy days I squandered, Many de songs I sung.

When I was playing wid my brudder happy was I.

Oh! Take me to my kind old mudder, Dere let me live and die.

One little hut among de bushes, One dat I love,

Still sadly to my mem'ry rushes, No matter where I rove.

When will I see de bees a humming all 'round de comb?

When will I hear de banjo tumming down in my good old home?

Example 11a: "Old Folks at Home" (1851), text

41 Emerson, p. 181.

42 Wiley Housewright, A History of Music and Dance in Florida 1565-1865 (Tuscaloosa: University of Alabama Press, 1991), 253. 


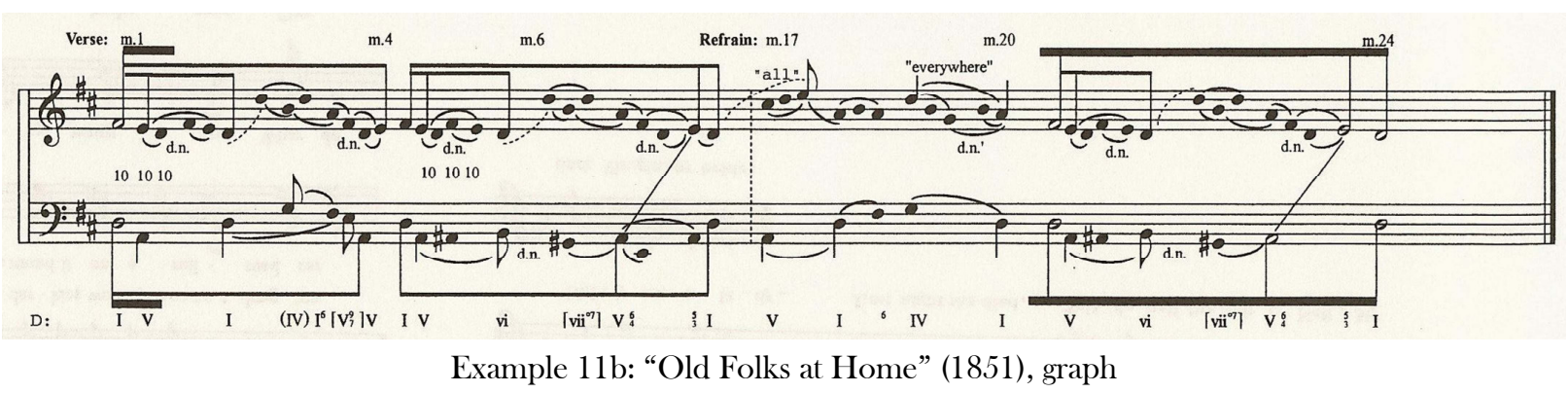

The song is quite simple in structure with only six phrases (Example 11b), all but one of which begins with a middleground descent from primary-tone $\mathrm{F}$ \# to the $\mathrm{D}$ tonic, with the $\mathrm{E}$ decorated by a double neighbor. The descent to $\mathrm{D}$ is one of Foster's rare linear progressions that does not correspond with an entire 4-bar phrase. In fact, the arrival on the low D motivates the song's signature octave leap, which is itself decorated by the pentatonic minor third down to B. Foster calls attention to the $\mathrm{D}$ throughout the song, especially in the refrain, where the $\mathrm{D}$ is emphasized by an upper and lower neighbor (m. 17). The $\mathrm{C \#}$ lower neighbor here is the only leading tone in the voice and the only scale-degree four appears two measures later (m.19). This brief departure from the pentatonic realm and its emphasis of the words "all" and "eberywhere" reflects the "sad and dreary" world that lies far from the verse's nostalgia. Indeed, the verse's octave leap to the $\mathrm{D}$ and the pentatonic minor third that follows it suggest an age-old yearning and a distance between the singer and home. Ultimately, the lack of stepwise descent from D suggests that the distance is untraversable and the yearning must remain unsatisfied.

A similar octave leap followed by a pentatonic minor third appears in "Massa's in de Cold Ground," (1852) which also resembles "Old Folks at Home" in form, meter, key, and pentatonic melody (Example 12a). Perhaps the popularity of "Old Folks at Home" inspired the composition of "Massa's in de Cold Ground." The nostalgia here, however, is not for the "Swanee" but for the recently passed master (Example 12b). Although the notion that slaves developed sentimental attachments to their masters is a matter of political and historical dispute, Foster's portrayal is nonetheless sympathetic, reflecting strong and serious emotions on the part of the slaves. The vignette described in this song suggests that Foster had found a new source of inspiration: Uncle Tom's Cabin. 


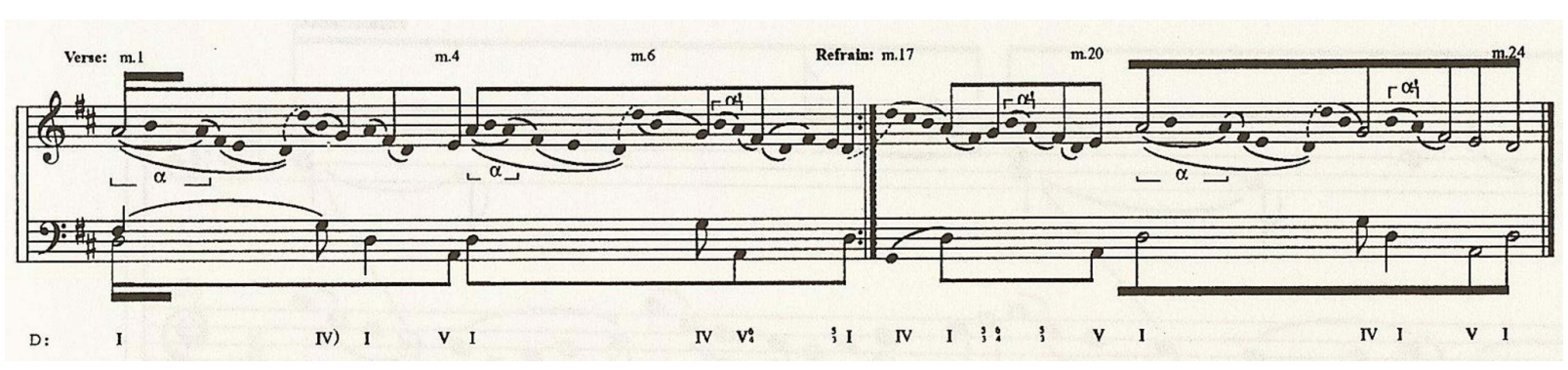

Example 12a: "Massa's in de Cold Ground,” (1852), graph

Massa made de darkeys love him,

Cayse he was so kind,

Now dey sadly weep above him

Mourning cayse he leave dem behind.

Example 12b: “Massa’s in de Cold Ground," (1852), verse 3, text

That Foster had finally gotten the formula correct for the new minstrel style was evidenced by the immediate and lasting success of "Old Folks at Home" and "Massa's in de Cold Ground." Indeed, when Uncle Tom's Cabin began its first serial run in 1851, Foster appeared to find his definitive voice as a minstrel composer. Harriet Beecher Stowe's novel fundamentally changed the northern perception of slavery. Many modern scholars claim that the novel only strengthened a pro-slavery sentiment by depicting Uncle Tom's passive resistance. Uncle Tom's Cabin was radical, however, in its realistic portrayal of slave-family separation. In addition, it was viewed as a serious anti-slavery statement by nearly all who read the first edition, even to the extent that it was banned in several of the southern states.

Oh! carry me 'long;

Der's no more trouble for me:

I's guine to roam in a happy home, Where all de niggas am free.

(sic)

Example 13: “Oh! Boys, carry me 'long” (1851) refrain, text

After the publication of Uncle Tom, Foster's music avoided any dehumanizing depictions of slaves. He offered a new and different image; one that "helped the American people to feel that the "slave was, after all, a human being, with the same joys and sorrows common to the rest of [human]kind." ${ }^{43}$ This is reflected in a letter that he sent to the Christy Minstrel singers with the manuscript for "Oh! Boys, carry me "long" (1851): "remember, it should be sung in a pathetic, not a comic style." ${ }^{44}$ This song depicts a slave's longing for freedom and his subsequent realization that only death will offer a chance for respite (Example 13). With this novel text and clear performance instructions, Foster set a new tone for minstrelsy.

43 “America's Foremost Balladist" Letters and Art 40/1 (1910): 21-22.

44 Ibid, 96. 

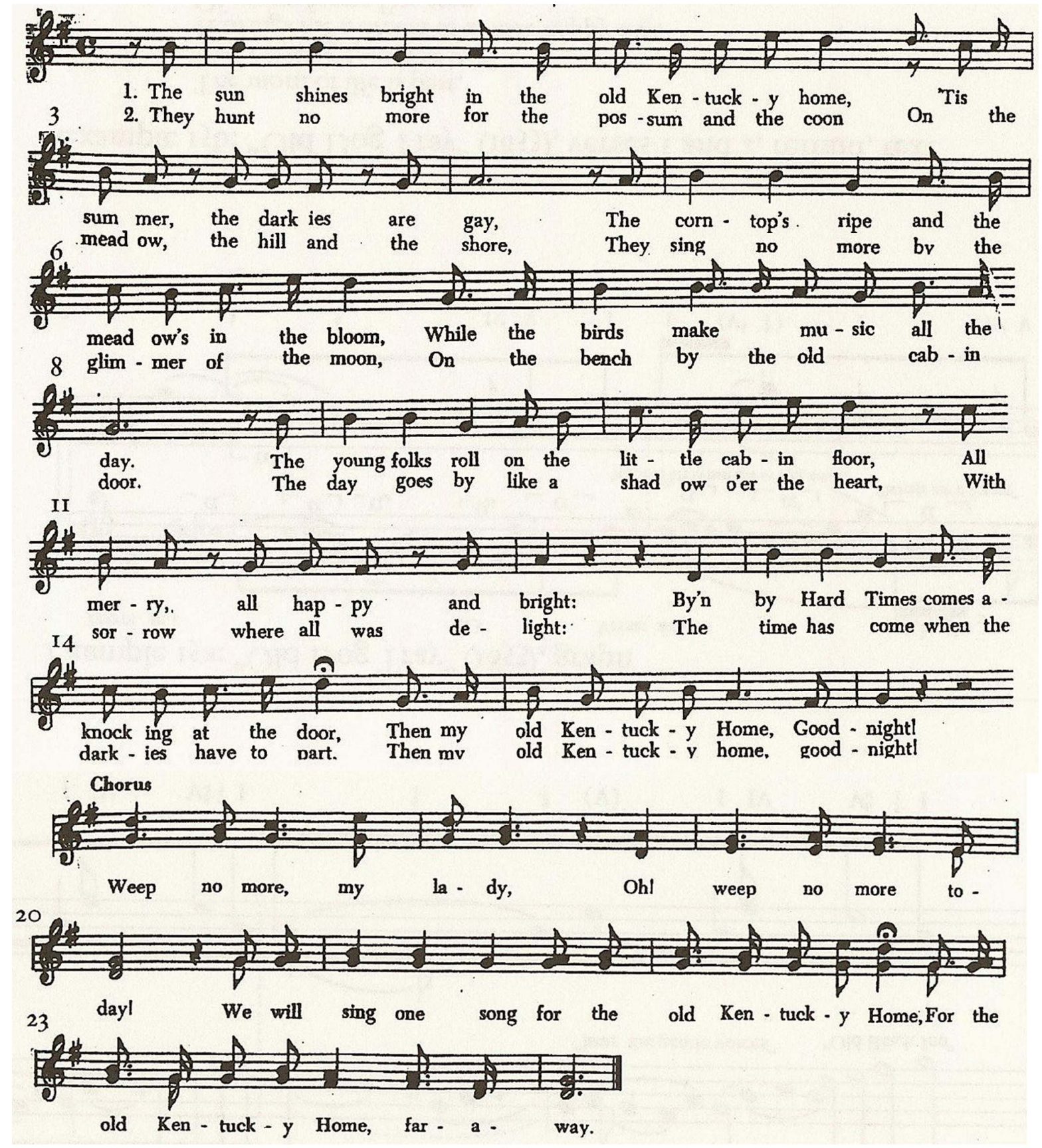

Example 14a: "My old Kentucky Home, Good night” (1853), melody 
There is little doubt that Stowe's novel affected Foster. He encouraged the use of his music in the staged versions of the novel, going so far as to set a song specifically for this purpose. "My old Kentucky Home, Good night” (1853), a song of extreme pathos, originally carried the title "Poor Uncle Tom, Good night" (Example 14a).$^{45}$ Foster made an important step when he scrapped the blackface dialect from his sketch of "My Old Kentucky Home," although he did leave the word "darkey." The sentiment of the song is universal; death as a relief for the world-weary (note the similarity with the text of "Oh! Boys, carry me 'long"). Its attribution to a slave confirms the transition to a completely new type of minstrel song. This is even clearer in the manuscript's original refrain, which is based on Stowe's Uncle Tom:

Oh good night, good night, good night

Poor Uncle Tom

Weep not for your old Kentucky home

Your bound for a better land,

Old Uncle Tom.

"My Old Kentucky Home" employs virtually the same 24-bar structure as "Old Folks at Home" (Example 14b). It also is similar in its use of scale-degree three as a primary tone, with an almost equally significant pitch, in this case scale-degree five, lying above it. A clear omission of scale-degree four and its consonant support thwarts a stepwise descent from scale-degree five to the tonic. Instead, after ascending by step to scale-degree five, the melody leaps directly to one, only to ascend to $\mathrm{B}$, the actual primary tone. The ascent followed by the fifth drop recalls "Old Uncle Ned" and his hardworking life. The equation of "Uncle Ned" and "Uncle Tom" is striking. Here is the ultimate manifestation of the ideals Foster had been harboring several years earlier.

The pauses in m.3 of the verse emphasize two non-chord tones, an A passing tone and an F\# neighbor, temporarily postponing their resolutions. These pauses are borrowed from the more sentimental world of the parlor ballad, such as "Jeanie with the Light Brown Hair," but can also be seen in songs such as "Old Dog Tray" and "Melinda May." The hesitations distance the protagonist from his memories of the "old Kentucky home." Foster further distances the protagonist from the "bright sun" of the verse by juxtaposing its B-D ascent (mm. 1-2) with the "weeping" descent from D-B in the refrain (mm. 17-18). Like "Old Folks at Home" and "Massa's in de Cold Ground," this song evokes longing and nostalgia through the B-D minor third.

Two later minstrel songs contain a similar motive: "Old Dog Tray," and "Old Black Joe." "Old Dog Tray" (1853) is Foster's only minstrel song with no mention of the slaves or the south (Examples $15 \mathrm{a}$ and $15 \mathrm{~b})$. The piano introduces the song's semitone-neighbor motive in the form of an F\#-G in the left hand and an A\#-B motion in the right (marked as alpha in Example 15a). The A\# is a pitchspecific reference to the light chromaticism of "Melinda May" and like that song, "Old Dog Tray" borrows from the italianate ballad style. The B-D minor third is particularly evident in the piano introduction, where the $\mathrm{D}$ is a cover tone over the $\mathrm{B}$ primary tone. The semitone-neighbor decorates each note in the verse's ascent to the primary tone. The first line of text, "the morn of life is past," starts on the $\mathrm{G}$ tonic, but pauses after the arrival on the leading-tone lower neighbor, recalling the 
verse of "My Old Kentucky Home." The second line of the text (m. 2), "and evening comes at last," transforms the motive into a whole-step upper neighbor, appropriately juxtaposing the "evening" with the "morning." Although the tonic reappears in the bass on the word "last," the melody holds the fifth of the chord, denying any sense of resolution from the emphasized $\mathrm{F} \#$ in the first bar of the verse. The A\# chromatic neighbor and the B-D minor third decorate the melody's arrival on the primary tone in $\mathrm{m}$. 3-a nostalgic touch, setting the word "dream." The F\# of bar one, which is restated in $\mathrm{m}$. 5 , finally fulfills its leading function with the arrival of the tonic cadence and the titular character "old dog tray" (m. 8). Indeed, we are told that this special dog fulfills all of the singer's needs (Example $15 \mathrm{~b})$. This protagonist differs from those of the previous songs. While expressing sadness for the loss of "lov'd ones, the dear ones" who "have all passed away," the singer is thankful for the current fellowship with Tray, a faithful dog. This may explain the frequent departure from the pentatonic world of Foster's earlier minstrel melodies.

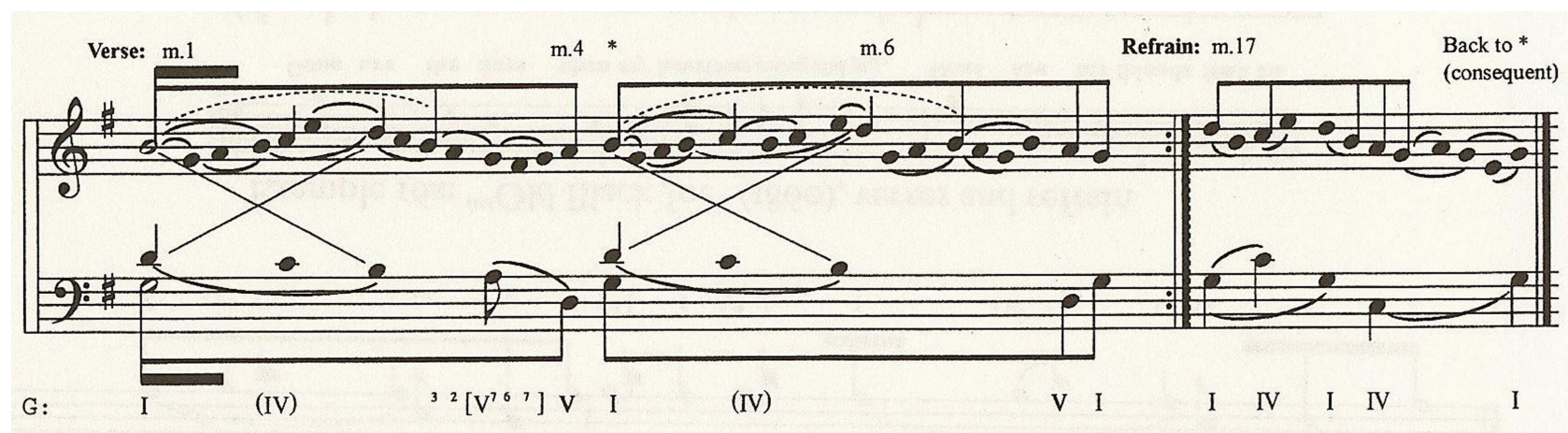

Example 14b: "My old Kentucky Home, Good night” (1853), graph of verse and first subphrase of refrain

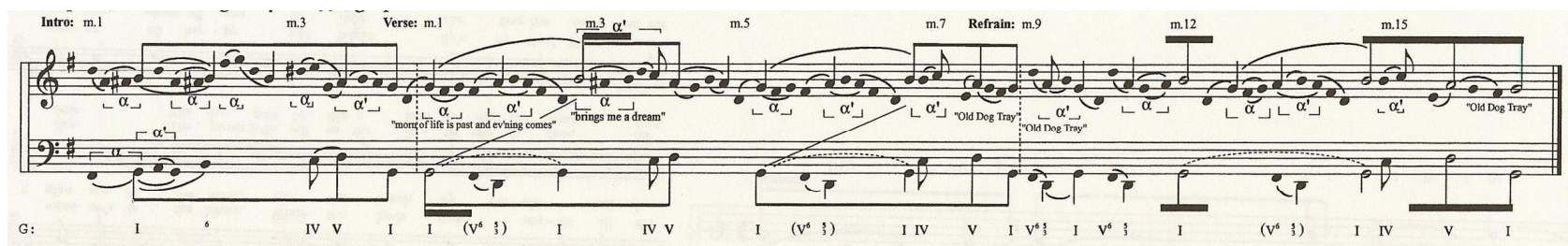

Example 15a: “Old Dog Tray” (1853), graph

45 The original title is crossed out in Foster's notebook. 


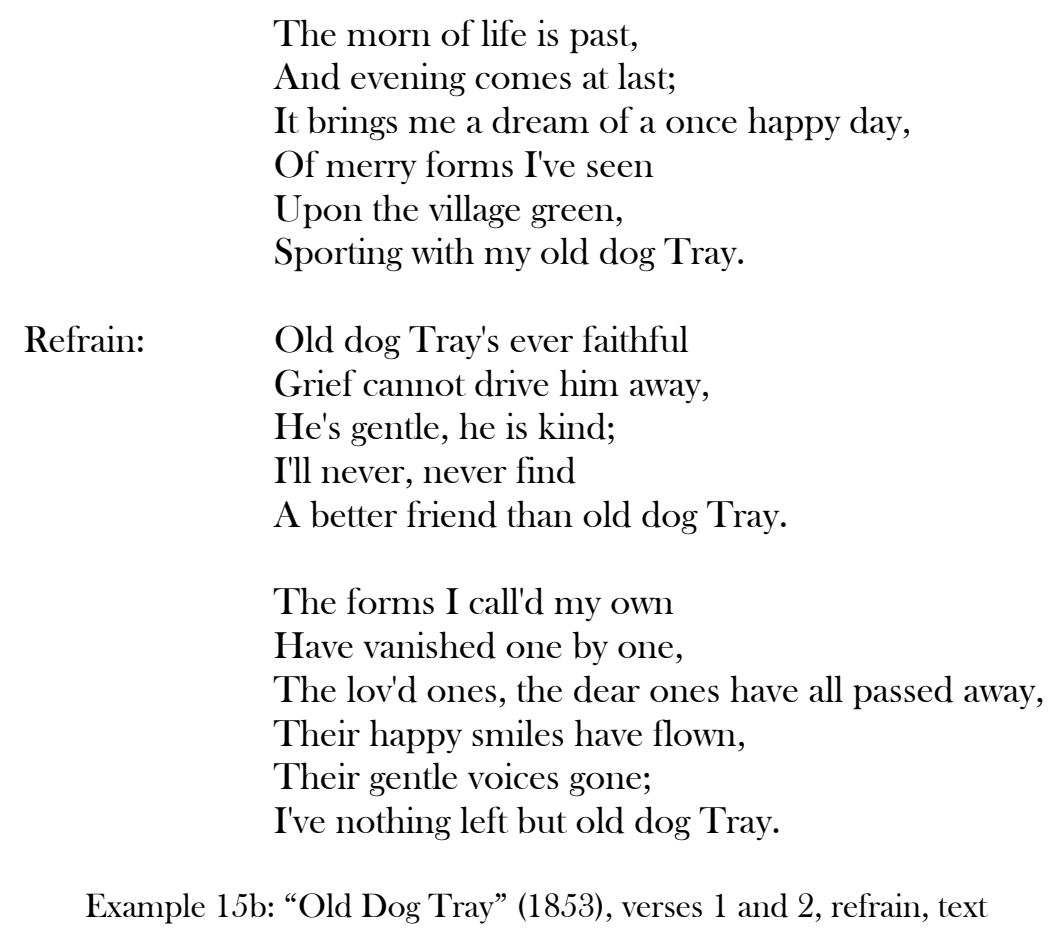

"Old Black Joe" (1860) is Foster's last true minstrel song and represents the ultimate distillation of his work in the genre. ${ }^{46}$ The text echoes the common themes of nostalgia for days past and a longing to leave the material world, but here the singer is a slave with no hint of dialect. The B-D motive from the earlier songs emphasizes Joe's nostalgic recall of days past: "heart was young" and "better land." The use of the scale-degree 6-8 third, however, does not indicate true pentatonic organization, for each $\mathrm{D}$ is followed or preceded by a $\mathrm{CH}$. A bare hint of the earlier pentatonicism is preserved by the special emphasis given to the pitches $\mathrm{A}, \mathrm{B}, \mathrm{D}$, and $\mathrm{E}$.

The formal outlay of this 12-measure song is quite unique. The verse consists of a single 8-bar phrase, with the first six measures setting up a typical antecedent-consequent design. Rather than repeating the material of the antecedent, however, the final two measures of the verse act as a climactic departure from the now thrice repeated melody. The bygone days of the first three lines of each verse are thus separated from the premonitions of the future suggested by the ever-repeating calling of the voices. The details of Joe's past are set poignantly in the fourth measure of every verse with a sharp major-seventh dissonance between the G\# passing tone in the bass and the $\mathrm{G}$ natural in the voice. The refrain, "I'm coming, I'm coming," sets Joe's reply to the voices with an A-F\#-A minor third, which reverses the contour of the nostalgic B-D as well as the initial ascent to A in the verse (Example 16b). The listener senses an eagerness in Joe's voice that contrasts with his feelings about the past. The final two bars of the refrain echo the persistently calling voices of the verse.

46 "A Soldier in the Colored Brigade" (1863) is a civil-war song and is quite different from the songs written between 1847 and 1860 in both content and purpose. "Don't Bet Your Money on de Shanghai" (1861) represents a rather desperate attempt to earn new royalties by returning to the faster-tempo style of the early minstrel songs. This song contains no mention of slaves or slavery. 

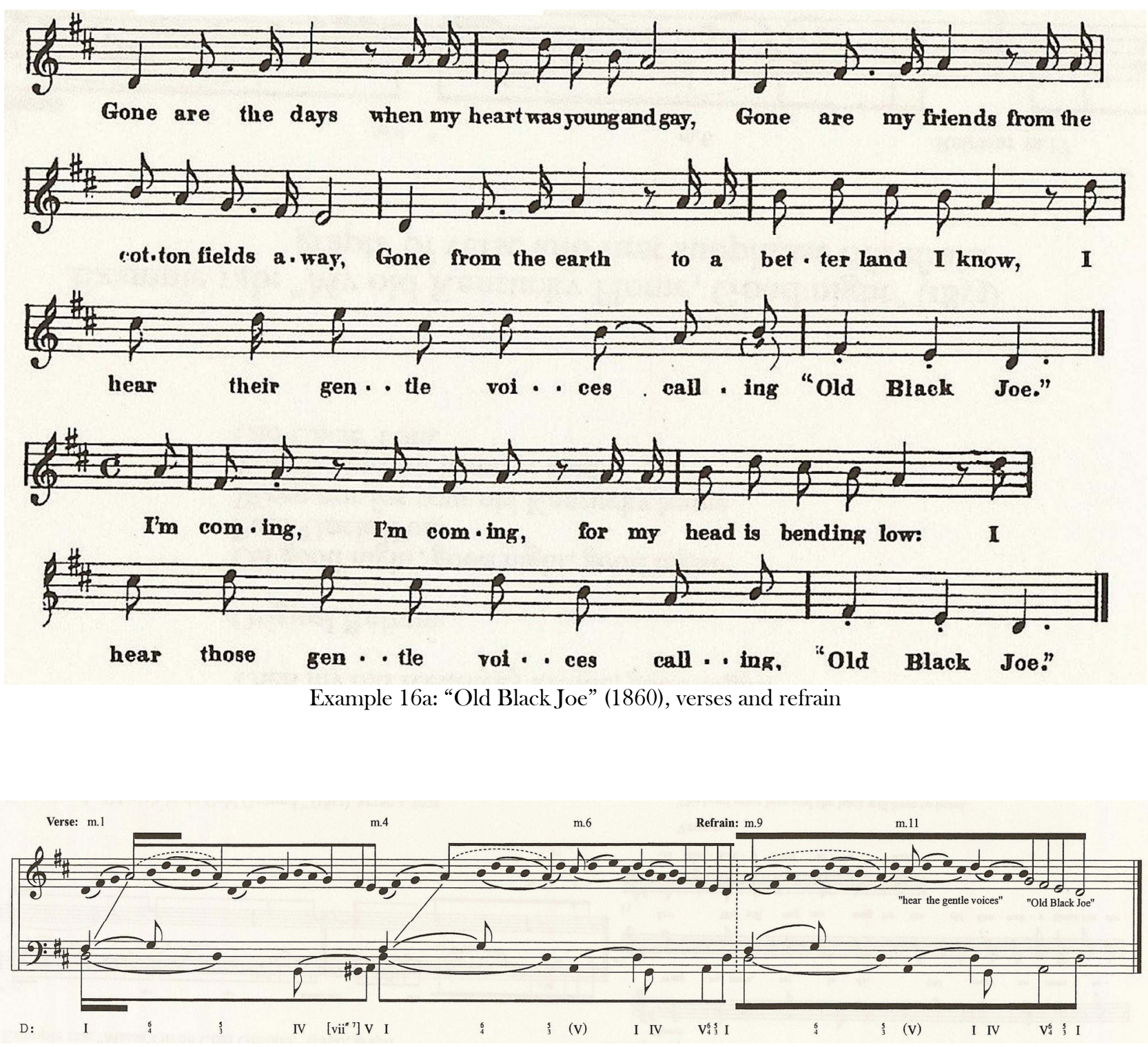

Example 16b: “Old Black Joe” (1860), graph

The brief prolongation of the leading tone, $\mathrm{C \#}$, in the penultimate bars of both refrain and verse connects the word "hear" with "voices," which is set to the tonic arrival (m. 11). The descent to tonic here is set out of phase with the harmony such that the unfolding thirds of "gentle voices" (E-C\#, D-B) places the $\mathrm{B}$ over a dominant chord and the $\mathrm{A}$, which it ultimately displaces, becomes a dissonance over a tonic chord. Foster avoids the continuation of the descent to $G$ on the final eighth note of "calling" in mm. 7 and 11, instead stepping up to B. This distances the titular phrase, which is placed in quotes, from the actual calling. Perhaps Joe is not completely ready to receive this message, but must first reconcile his past. "Old Joe" is a complex and noble character-a far cry from the slaves of "Oh! Susanna" and "Away down Souf." Joe and Uncle Tom evoke the same empathy, which may be 
why W. E. B. Du Bois found "Old Black Joe" and the earlier "Old Folks at Home" to be the two songs in this genre that were worthy of praise. ${ }^{47}$

The solidification of Foster's revised minstrel style can be seen in his changing of genre names, from 'Ethiopian Songs' to 'Plantation Melodies'. In addition, Foster wrote a letter to the Christy minstrels in 1852 stating that he wished to return his name to the cover of "Old Folks at Home":

As I once intimated to you, I had the intention of omitting my name on my Ethiopian songs, owing to the predudice against them...but I find that by my efforts I have done a great deal to build up a taste for the Ethiopian songs among refined people by making the words suitable to their taste, instead of the trashy and really offensive words which belong to some songs of the order...I have concluded to... pursue the Ethiopian business without fear or shame.

He goes on to say that he would like to become the "best Ethiopian song writer," in marked opposition to his earlier attempts to distance himself from the genre. ${ }^{48}$ Perhaps his new approach to the minstrel song had helped to ease his conscience.

Stephen Foster's perception of slavery developed dramatically between 1847 and 1860. In a period of increasing political tension, Foster's new "plantation melodies" may have shifted the focus of northern audiences, subtly directing them to question the misrepresentations of slave life in earlier minstrel works. Indeed, Eric Lott suggests that the drastic revision of the minstrel style was a harbinger of the armed conflict that was to come:

Stephen Foster's 'Plantation Melodies' unwittingly conjured up the hydra-headed [political] conflicts [of the era]; these melodies, and the vast dissemination of Uncle Tom's Cabin in various politically divergent blackface theatrical productions [were] a kind of prelude to civil war on the stage [and they] offer a lens through which to read a political crisis...a revolution on American soil. ${ }^{49}$

Although Foster's early minstrel songs promote the dehumanizing stereotypes of contemporaneous blackface performance, his later "plantation melodies" are essentially non-ethnic in content.

In a speech to the Rochester Ladies' Anti-Slavery Society in 1855, Frederick Douglass lauded Foster's new minstrel style:

Considering the use that has been made of them, that we have allies in the Ethiopian songs... “Old Kentucky Home," and "Uncle Ned," can make the heart sad as well as merry, and can call forth a tear as well as a smile. They awaken the sympathies for the slave, in which antislavery principles take root and flourish..$^{50}$

These songs explore universal themes of humanity-love, nostalgia, and longing-in both their text and their music. Through their association with the blackface minstrel show, they reinforced a new understanding of slaves and slave life, allowing Stephen Foster to add his musical support to the antislavery movement.

47 W. E. B. Du Bois, “The Souls of Black Folk,” in Writings, ed. Nathan Huggins (New York: Viking Press, 1986), 540.

48 Letter to E.P. Christy, May 25, 1852.

49 Lott, 8.

50 Philip Foner, Ed., The Life and Writings of Frederic Douglass (New York: International Publishers, 1950), $356-357$. 